\title{
Background trends in California Current surface chlorophyll concentrations: A state-space view
}

\author{
Andrew C. Thomas, ${ }^{1}$ Roy Mendelssohn, ${ }^{2}$ and Ryan Weatherbee ${ }^{1}$ \\ Received 7 May 2013; revised 17 August 2013; accepted 19 August 2013.
}

[1] State-space models are applied to 13 years of monthly satellite-measured chlorophyll concentrations of the California Current, from British Columbia to Baja California, to isolate the slowly varying background trend from potentially nonstationary seasonal cycles, other higher-frequency cyclical variability, and an irregular plus measurement error signal. Temporal patterns in resulting background trends cluster into four dominant groups, three of which have increasing trends, the strongest of which extends over the coastal upwelling region from southern Oregon to Point Conception, California, and has a mean of $0.118 \mathrm{mg}$ CHL m ${ }^{-3}$ decade $^{-1}$. Overall, statistically significant increasing trends are observed over $75 \%$ of the study area, $20 \%$ of the study area had no trend, and $5 \%$ showed decreasing chlorophyll. Location-specific trend estimation shows increases are strongest $(>0.2 \mathrm{mg}$ CHL m ${ }^{-3}$ decade $^{-1}$ ) in upwelling areas along the Washington, Oregon and central California coasts, weaker in regions $>200 \mathrm{~km}$ offshore, and that positive trends are statistically significant over most of the California Current north of $\sim 27^{\circ} \mathrm{N}$. Negative trends are evident south of $\sim 31^{\circ} \mathrm{N}$ off Baja California. These trends remain significant with similar spatial pattern, but lower magnitude, when the 1997-1998 El Niño period is removed from the analysis. State-space models of trends in alongshore wind stress and sea surface temperature over the same period indicate that local mechanisms linked to these chlorophyll trends are not clear. Comparisons of the chlorophyll trends to nonlocal signals, characterized by the North Pacific Gyre Oscillation and the Multivariate El Niño Index, map the spatially varying ecological footprint of these basin-scale signals.

Citation: Thomas, A. C., R. Mendelssohn, and R. Weatherbee (2013), Background trends in California Current surface chlorophyll concentrations: A state-space view, J. Geophys. Res. Oceans, 118, doi:10.1002/jgrc.20365.

\section{Introduction}

[2] Phytoplankton mediate the transfer of energy into higher trophic levels, including those of socioeconomic importance [Ware and Thomson, 2005], and play a key role in global biogeochemical cycles. Quantifying temporal trends in phytoplankton concentrations and variability in spatial distribution patterns is an important aspect of understanding both the ecosystem and the biogeochemical components of the oceanic response to global climate change [Antoine et al., 2005; Martinez et al., 2009; Irwin and Oliver, 2009; Boyce et al., 2010]. Persistent wind-driven upwelling, nutrient enrichment of the euphotic zone, and resulting elevated phytoplankton concentrations make

\footnotetext{
${ }^{1}$ School of Marine Sciences, University of Maine, Orono, Maine, USA. ${ }^{2}$ NOAA Southwest Fisheries Science Center, Pacific Grove, California, USA.

Corresponding author: A. C. Thomas, School of Marine Sciences, University of Maine, 5706 Aubert Hall, Orono, ME 04469-5706. USA (thomas@maine.edu)
}

(C)2013. American Geophysical Union. All Rights Reserved. 2169-9275/13/10.1002/jgrc.20365 eastern boundary currents (EBCs) some of the most biologically productive regions in the global ocean [Mackas et al., 2006]. Bakun [1990] suggested that climate-related warming might occur faster over continents than over the ocean, thereby increasing the continent-ocean pressure gradient that drives the alongshore wind stress of EBC regions. This would increase coastal upwelling and surface nutrient supply, reduce sea surface temperatures (SSTs), and drive increasing concentrations of phytoplankton.

[3] Schwing and Mendelssohn [1997] show that such an increasing trend in coastal upwelling appears to be present in the California Current, at least during upwelling season from the Southern California Bight to $\sim 40^{\circ} \mathrm{N}$. Belkin [2009] shows that both the California and Humboldt Current regions exhibit decreasing SST trends over the past four decades. Satellite-estimated primary production for the California Current has a positive trend over the 19972007 period adjacent to the coast (the first $50-100 \mathrm{~km}$ ) over most of the region from Baja California to Washington [Kahru et al., 2009]. Trends away from the immediate coastal upwelling region were insignificant. These authors also show that the summer seasonal maximum is increasing in regions off central, southern and Baja California, but point out that these patterns are not correlated with the 
upwelling index or local SST. Using an empirical approach to synthesize a multisensor time series from four different satellite ocean color sensors, Kahru et al. [2012] expand the time scale of this view, showing that 15 years of data from the period 1997-2011 have increasing trends in chlorophyll anomalies off central and southern California but decreasing trends off southern Baja California. Their results show no significant trends north of $\sim 40^{\circ} \mathrm{N}$. Off Baja California, the dominant statistical mode of a nonseasonal chlorophyll time series from 1998 to 2002 shows low values during the 1998 El Niño period, but no overall trend [Espinosa-Carreon et al., 2004]. Over the entire California Current region, the dominant statistical mode of nonseasonal chlorophyll shown by Thomas et al. [2012] has a positive trend. However, the extent to which background trends in chlorophyll concentration in this productive $\mathrm{EBC}$ region are hidden, and/or biased, by error/noise, strong episodic events, and potentially nonstationary seasonal variability that remain in simple anomaly time series is not clear.

[4] A coupled climate model over the Pacific shows increasing chlorophyll concentrations over the California Current region in the next century [Hazen et al., 2012]. Contrarily, stratification [Palacios et al., 2004] and surface warming [Di Lorenzo et al., 2005] appear to be increasing in the California Current, both of which would reduce vertical nutrient flux and phytoplankton production. Global views suggest that increases in chlorophyll concentration are taking place over the past 10 years [Vantrepotte and Mélin, 2009] at some locations off California. Increasing trends over some regions of the California Current are among the larger trends observed in the global ocean [ Vantrepotte and Mélin, 2011]. This is consistent with global views of SST trends that show localized decreasing trends off northern California [Burrows et al., 2011] and for the overall California large marine ecosystem [Belkin, 2009].

[5] Over the extent of the California Current, a body of work has established that there exists a strong regionality in both physical forcing [e.g., Mendelssohn and Schwing, 2002; Bograd et al., 2009] and phytoplankton response [e.g., Kahru and Mitchell, 2001; Legaard and Thomas, 2006; Thomas et al., 2009]. Such spatial heterogeneity is controlled by latitudinal differences in the impact of basin-scale signals, superimposed on latitudinal gradients in the strength and seasonality of wind forcing, heating and light, and differences in coastline morphology. This suggests that the impact of climate changeinduced increases in upwelling-favorable winds is likely to be regionally specific within EBC regions. Furthermore, the strong seasonality [Legaard and Thomas, 2006], shifts in phenology [Palacios et al., 2004; Bograd et al., 2009], and/or episodic events [Barth et al., 2007] characteristic of the California Current, each of which create strong anomalies, might mask or bias underlying background trends.

[6] Here, state-space models are applied to satellitemeasured ocean color data to separate any slowly varying background component in chlorophyll concentration time series from higher-frequency components such as seasonality, changes in phenology, other cyclical/autocorrelated variability and episodic events. We do this in a locationspecific manner to present a spatial geography of underlying chlorophyll trends over the latitudinal extent of the California Current system, from British Columbia to Baja California (Figure 1). We use 13 years of SeaWiFS satellite

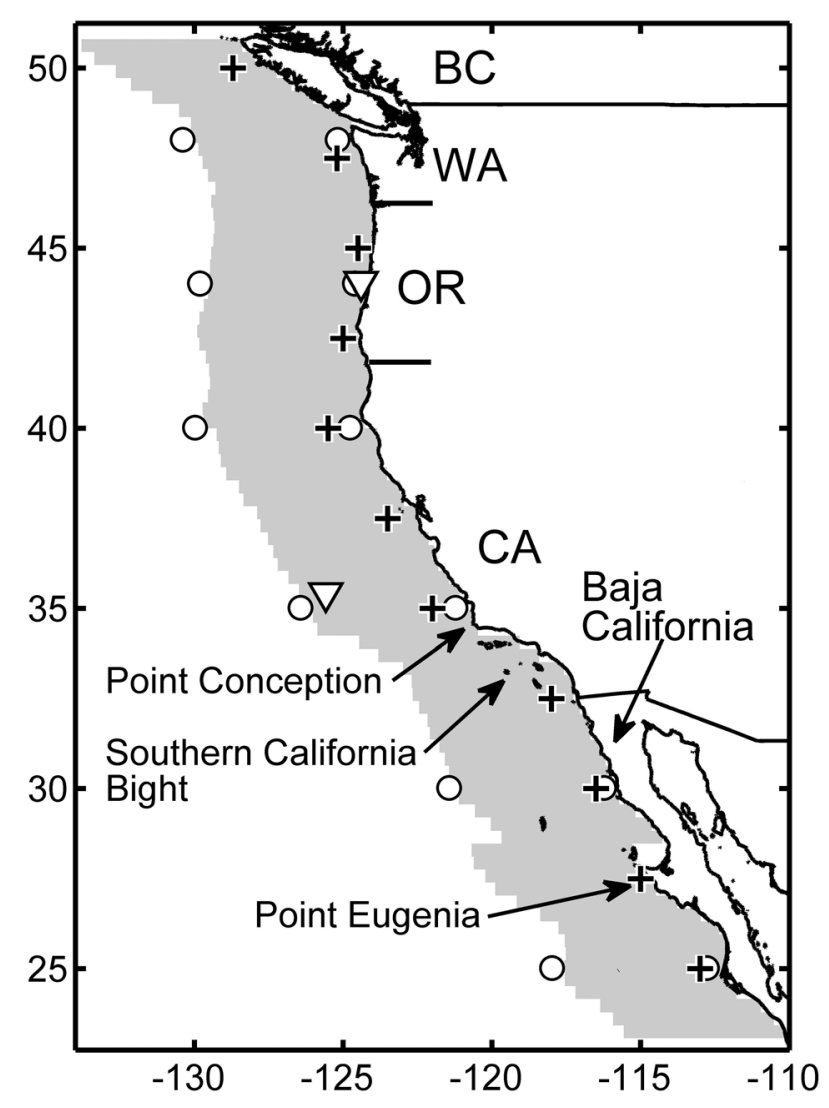

Figure 1. The California Current study area showing major geographic locations, boundaries between political units, the area of chlorophyll analysis (gray), and the locations of alongshore wind stress (plus symbol), SST (open circle) sampling, and of two example locations used in Figure 2 (inverted triangle).

ocean color data, a consistently processed time series of chlorophyll measurements from a single instrument, to test the hypothesis that chlorophyll concentrations have increased in the California Current. By using data from a single sensor, we avoid issues created by differing measurement techniques [e.g., McQuatters-Gollop et al., 2011] and/or different satellite sensor characteristics that require location-specific empirical correction [e.g., Kahru et al., 2012]. The SeaWiFS data allow systematic views over the entire latitudinal extent of the California Current. The state-space models isolate any slowly varying background trend of interest. We provide maps that show the regional geography of observed trends and quantify their overall magnitude. We then compare these results to time series of wind forcing and sea surface temperature to develop a picture of recent surface ecosystem trends in relation to concurrent local physical processes and quantify the footprint of climate-related signals from the North Pacific on chlorophyll trends to provide a view of nonlocal forcing.

\section{Data and Methods}

\subsection{Data}

[7] Daily $4 \mathrm{~km}$ resolution SeaWiFS chlorophyll retrievals using the standard NASA algorithm [O'Reilly et al., 
1998] (reprocessing version R2010) from the entire mission, September 1997 to December 2010, were acquired from the NASA Ocean Color archive and remapped to a consistent projection over the California Current region (Figure 1) from the northern tip of Vancouver Island to the southern tip of Baja California $\left(51^{\circ} \mathrm{N}\right.$ to $\left.23^{\circ} \mathrm{N}\right)$. Comparisons to in situ measurements show the NASA standard band-ratio algorithm performs well over the study area [Kahru and Mitchell, 1999]. Monthly composites were formed as geometric means from the daily data to reduce noise and gaps due to clouds, and these composites were subsampled to include the region $600 \mathrm{~km}$ west of the coast over the latitudinal extent of the study area (Figure 1). Mission difficulties as the satellite aged resulted in data gaps in 2008 and 2009, the longest of which is a 3 month gap in early 2008. To reduce the size of the data matrix to be treated, we take advantage of extended alongshore correlation length scales compared to those in the cross-shelf direction [Denman and Freeland, 1985], and further subset these data by first median smoothing over 7 pixels $(28 \mathrm{~km})$ in the alongshore direction and then sampling every 10 th line in latitude. The final chlorophyll data set we analyze for trends in concentration retains the original $4 \mathrm{~km}$ crossshelf resolution at each latitude, has $40 \mathrm{~km}$ resolution in the alongshore direction, and is 160 months in time. These chlorophyll time series were log transformed [Campbell, 1995] prior to analysis.

[8] Wind data are monthly averaged stress components over the study period from the Blended SeaWinds product, available on a $0.25^{\circ}$ latitude-longitude grid, and acquired from the National Climate Data Center (http://www.ncdc. noaa.gov/oa/rsad/air-sea/seawinds.html). This product blends wind speeds from multiple satellites and uses NCEP Reanalysis 2 to provide directions. Stress vectors were subset to 11 locations close to the coast over the latitudinal extent of the study area (Figure 1). At each location, monthly values represent the median of a $0.75^{\circ} \times 0.75^{\circ}$ box centered at the target location and the alongshore component of wind stress calculated using the local coarsescale $(\sim 200 \mathrm{~km})$ angle of the coastline.

[9] Surface temperature data over the study period are Pathfinder Version 5.2 satellite SST monthly means at 4 $\mathrm{km}$ resolution calculated from daily daytime passes that were of quality grades 5-7 (acceptable - best quality). Data are served from the U.S. National Oceanographic Data Center (ftp://data.nodc.noaa.gov/pub/data.nodc/pathfinder/). SST time series were subset from 12 locations, representing six latitudes, each with a location within the $12 \mathrm{~km}$ of the coast and one $600 \mathrm{~km}$ offshore (Figure 1).

\subsection{State-Space Models}

[10] Satellite-observed variability within the monthly chlorophyll time series reflects multiple underlying forcing components plus "measurement error," which can include highly anomalous, one-time events that can otherwise skew analysis. The monthly composites smooth higher (daily and weekly)-frequency variability such as that induced by synoptic storms and individual upwelling events of several days. However, even within the monthly time series, episodic events, any cyclical or autoregressive responses to events, seasonal variability, and measurement error are each superimposed on any overall trends we wish to isolate and quantify. Among these, seasonal components cannot necessarily be assumed to be stationary [ $\mathrm{Ji}$ et al., 2010; D'Ortenzio et al., 2012] and at least one strong basin-scale interannual signal known to be associated with strong anomalies, the 1997-1998 El Niño [Kahru and Mitchel, 2000; Legaard and Thomas, 2006], occurred at the beginning of the time series, potentially biasing parametric trend calculations. Specific individual forcing events lasting more than a month that impact the chlorophyll seasonal cycle are well documented in the California Current. These include anomalous equatorward transport of nutrient-rich subarctic water in 2002 [Bograd and Lynn, 2003; Thomas et al., 2003] and delayed upwelling winds in 2005 [Barth et al., 2007]. Here we use state-space models to separate underlying background trends from higher-frequency variability. State-space models offer a highly flexible methodology for time series analysis [Durbin and Koopman, 2001]. In state-space analysis, development over time of a study system is assumed to be observed imperfectly as observations $\mathrm{y}(\mathrm{t})$ that result from a combination of underlying, but unobserved, vectors $\alpha(\mathrm{t})$, and the relationships between $\alpha(\mathrm{t})$ and $\mathrm{y}(\mathrm{t})$ are specified by the state-space models, to be inferred from the observations $\mathrm{y}(\mathrm{t})$. The $\alpha(\mathrm{t})$ are constrained to be piecewise continuous smoothing splines and solved using combined maximum likelihood and Kalman filter techniques. The user provides potential models, based on a priori knowledge if possible. In this case, a possible slowly varying underlying background trend and an assumption of a possibly changing seasonal cycle provide reasonable starting points. Quantitative metrics combined with quantitative and graphic examination of residuals behavior for normality, independence, and homoscedasticity then allow judgment about the relative success of different models [Commandeur and Koopman, 2007]. Apart from the flexibility to specify a wide assortment of models for testing, two appealing characteristics of the methodology are that none of the resulting models, including the background trend or any seasonal component, necessarily have to be stationary or deterministic, and missing data are handled gracefully. State-space models see extensive use in the social sciences and econometrics [e.g., Harvey and Durbin, 1986; Wang et al., 2012], have been widely applied in ecology [e.g., Wang and Getz, 2007; de Valpine and Rosenheim, 2008], and are seeing increasing application in marine sciences [e.g., Jonsen et al., 2003, 2005; Mendelssohn et al., 2003, 2005; Fiedler et al., 2012]. The approach belongs to the same family of modeling as the Census X-11 procedure applied to global satellite-measured chlorophyll data by Vantrepotte and Mélin [2011].

[11] Most applications of state-space models in the literature proceed as a detailed analysis of a single, or a few, time series, testing numerous possible models for best fit. Here we wish to treat $>11,000$ time series, and examination of all residual series is not practical. It is unreasonable to expect the same model to fit equally well in every location, but the use of consistent models across all locations has obvious advantages for interpretation. We tested a suite of models on chlorophyll series from a subset of 10 locations chosen to be representative of differing chlorophyll mean concentrations and seasonal/interannual variability over the extent of the study area identified from previous time/space analyses, such as the Southern California Bight, 
the Baja California, northern, central California, Oregon and Washington upwelling regions, and offshore (western) areas of the study area [e.g., Legaard and Thomas, 2006; Thomas et al., 2009, 2012]. The models tested included (i) a time varying trend term, (ii) three different parameterizations of a seasonal term, and (iii) a cycle term to represent possible autocorrelated components, and combinations of these, all with a stationary uncorrelated irregular term, for a total of 15 different models at each of the test locations. Suitability of the models was judged by examination, both graphically and numerically, of the residuals for normality, independence (lack of autocorrelation, especially at short (1-3 month) lags and at annual periods), and overall effectiveness quantified by the Akaike Information Criterion (AIC), a metric that compensates for the number of estimated parameters in a model. The AIC does not provide any geophysical insight into the suitability of a model but provides an equitable quantitative comparison between models, including between models with differing numbers of parameters, penalizing the use of too many. We chose the two models that provided the best overall fit (most normally distributed and independent error) among the test sites and applied these to all locations and then retained the model with the lowest AIC at each location. This procedure provided a consistent and reasonably optimized modeling across the study area with the acknowledgement that at some specific, untested, locations a better model may be possible. The selected state-space models decompose the monthly chlorophyll signal at each grid location into either (a) model 1, a background trend $(T)$, a potentially nonstationary seasonal component $(S)$, and an irregular residual, observation error component (e), or (b) model 2, the same model with an additional cycle term $(C)$,

$$
\begin{aligned}
& \text { Model 1: } \log [\mathrm{CHL}]_{\mathrm{t}}=T_{\mathrm{t}}+S_{\mathrm{t}}+\mathrm{e}_{\mathrm{t}} \text {, and } \\
& \text { Model 2: } \log [\mathrm{CHL}]_{\mathrm{t}}=T_{\mathrm{t}}+S_{\mathrm{t}}+C_{\mathrm{t}}+\mathrm{e}_{\mathrm{t}}
\end{aligned}
$$

[12] The seasonal component has zero mean and is not constrained to be stationary or deterministic. The error component has zero mean, is stationary, independent, and approximately normally distributed. Although termed "error," these residuals certainly contain real episodic events and chlorophyll variability not well captured by the other model components, in addition to actual measurement error. The cycle term contains stationary autocorrelated components, with zero mean but potentially varying phase and amplitude. In this manner, the cycle can be thought of as a more general response than a purely autoregressive term. It is effective in modeling any stationary variability that is poorly modeled by the seasonal component that is constrained to a 12 month period, but is not independent and normally distributed as in the error component. In its simplest form, it could be a pure sine wave, but the state-space implementation allows this to potentially be damped (in time) and/or to have varying phase and amplitude. Such signals are often a component of oceanic geophysical variability [e.g., Fiedler et al., 2012], represent different processes than does a longterm trend, and these stationary components need to be removed if the nonstationary trend is to be isolated successfully. The trend is the slowly time varying, nonlinear and nonparametric, background signal of interest here.
[13] In state-space models, the trend term is viewed as an unknown function of time, and parameterized as

$$
\nabla^{k} T_{t} \sim N\left(0, \sigma_{T}^{2}\right) \quad t=1 \ldots \tau
$$

[14] where $\nabla$ is the lag difference operator, $k$ is the amount of the lag which is equal to 1 for all our analysis, $N\left(0, \sigma_{T}^{2}\right)$ denotes a random variable that is normally distributed with mean 0 and variance $\sigma_{T}^{2}$, which is estimated and controls the smoothness of the estimated trend, over the series $t=1 \ldots \tau$. The trend gives a nonparametric estimate of the change of the local mean of the series with time. In our model of the seasonal component, we constrain the running sum of the seasonal component $(S)$ as follows:

$$
\sum_{i=0}^{s-1} S_{t-1} \sim N\left(0, \sigma_{s}^{2}\right) \quad t=1 \ldots \tau
$$

[15] where $\sigma_{s}^{2}$ is estimated and controls the smoothness of the estimated seasonal component, and $s=12$ for monthly data. The state-space specification of the stationary cyclic term is

$$
\left[\begin{array}{c}
\psi_{t} \\
\psi_{t}^{*}
\end{array}\right]=\rho\left[\begin{array}{cc}
\cos \lambda_{c} & \sin \lambda_{c} \\
-\sin \lambda_{c} & \cos \lambda_{c}
\end{array}\right]\left[\begin{array}{c}
\psi_{t-1} \\
\psi_{t-1}^{*}
\end{array}\right]+\left[\begin{array}{c}
k_{t} \\
k_{t}^{*}
\end{array}\right] \quad t=1 \ldots \tau
$$

[16] where $\psi_{t}$ and $\psi_{t}^{*}$ are the states, $\lambda_{c}$ is the frequency, in radians, in the range $0<\lambda_{c} \leq \pi, k_{t}$ and $k_{t}^{*}$ are two mutually uncorrelated white noise disturbances with zero means and common variance $\sigma_{k}^{2}$, and $\rho$ is a damping factor. The damping factor $\rho$ accounts for the time over which a higher amplitude event (a disturbance to the series) in the stochastic cycle will contribute to subsequent cycles. A stochastic cycle has changing amplitude and phase, and becomes a first-order autoregression if $\lambda_{c}$ is 0 or $\pi$. Moreover, it can be shown that as $\rho \rightarrow 1$, then $\sigma_{k}^{2} \rightarrow 0$ and the stochastic cycle reduces to the stationary deterministic cycle:

$$
\psi_{t}=\psi_{0} \cos \lambda_{c} t+\psi_{0}^{*} \sin \lambda_{c} t \quad t=1 \ldots \tau
$$

[17] The observation errors are assumed to be zero mean, independent, and identically distributed as

$$
e(t) \sim N\left(0, \sigma_{e}^{2}\right) \quad t=1 \ldots \tau
$$

[18] Maximum likelihood estimates of the unknown parameters $\left(\sigma_{T}^{2}, \sigma_{S}^{2}, \sigma_{k}^{2}, \lambda, \rho\right)$ in the state-space model are obtained from the prediction error decomposition that is computed using the output of the Kalman filter [Commandeur and Koopman, 2007; Commandeur et al., 2011; Durbin and Koopman, 2001]. A Kalman smoother using the maximum likelihood estimates is then used to compute the mean and variance of smoothed variables. Modifications of the Kalman filter and smoother to handle missing data are described by Durbin and Koopman [2001]. Intuitively, since for fixed parameters the Kalman filter and smoother can be viewed as a Bayesian updating technique for normally distributed data, missing data are handled by propagating the prior distribution. Our calculations were performed using the 
freely available Matlab library SSMMatlab (http://www. sepg.pap.minhap.gob.es/sitios/sepg/en-GB/Presupuestos/Doc umentacion/Paginas/SSMMATLAB.aspx).

[19] While not the actual way that the algorithm works, the fitting procedure can be thought of in terms of the backfitting algorithm used in, for example, General Additive Models. At each iteration, a smoothing spline is fit to the partial residual series for each component. So for the trend, the present estimate of the seasonal and cyclic components are removed from the data (the result is called the partial residual), and a smoothing spline is fit to that partial residual. A similar calculation is done for the seasonal and cyclic terms to complete the iteration. More detailed information on state-space methods is available in textbooks [Durbin and Koopman, 2001; Commandeur and Koopman, 2007] and in a special volume 41 of Journal of Statistical Software devoted to state-space models, available at http:// www.jstatsoft.org/v41.

[20] An example of the state-space modeling results at two locations (see Figure 1) is shown in Figure 2, contrast- ing an example where the four-component model (model 2) was superior and its trend component was retained (Figures $2 \mathrm{a}$ and $2 \mathrm{~b}$ ) and one where the three-component model (model 1) had the lowest AIC and its trend component was retained for analysis (Figures $2 \mathrm{c}$ and $2 \mathrm{~d}$ ). Note that the AIC value is based on the prediction error from the Kalman filter, not from the smoothed estimate of the residual series, so the magnitude of the smoothed residual series shown is not necessarily reflective of the log likelihood of the model. For the retained models at these two locations (Figures $2 \mathrm{a}$ and $2 \mathrm{~d}$ ), the variances (as a percent of original variance) in each component are: Figure $2 \mathrm{a}, 25.8 \%, 10.5 \%, 43.9 \%$, and $19.8 \%$ for the seasonal, trend, cycle, and residual components, respectively, and for Figure 2d, 38.6\%, 9.9\%, and $51.5 \%$ for the seasonal, trend, and residuals, respectively. The trends of interest are typically a relatively small component of the total variance, but this is not unusual in biophysical systems where higher variance is often in the higher-frequency terms, such as the seasonal, the cycle, and/or uncorrelated components. This does not negate the

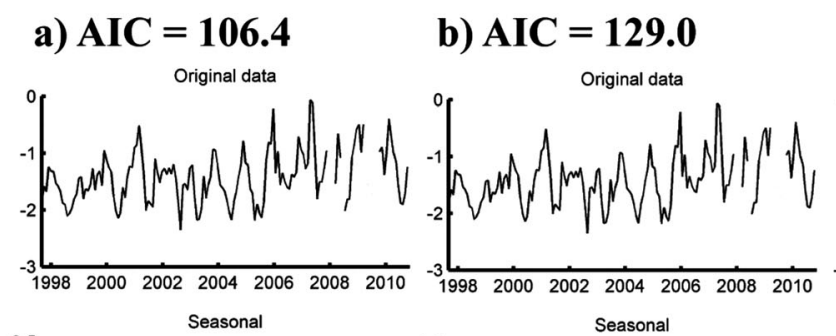

c) $\mathrm{AIC}=\mathbf{2 7 2 . 0}$

Original data

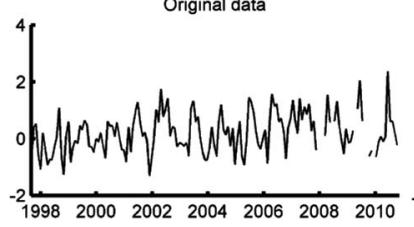

\section{d) $\mathrm{AIC}=268.5$}

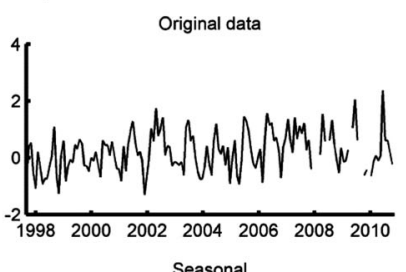

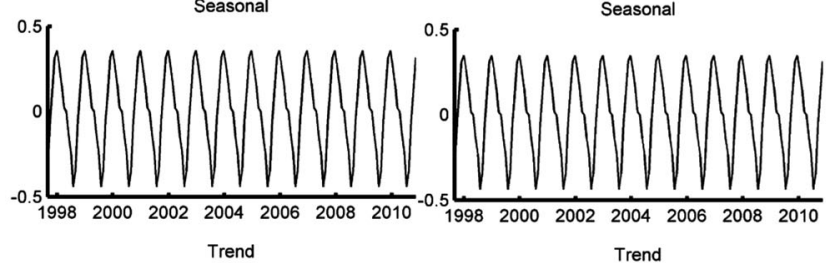
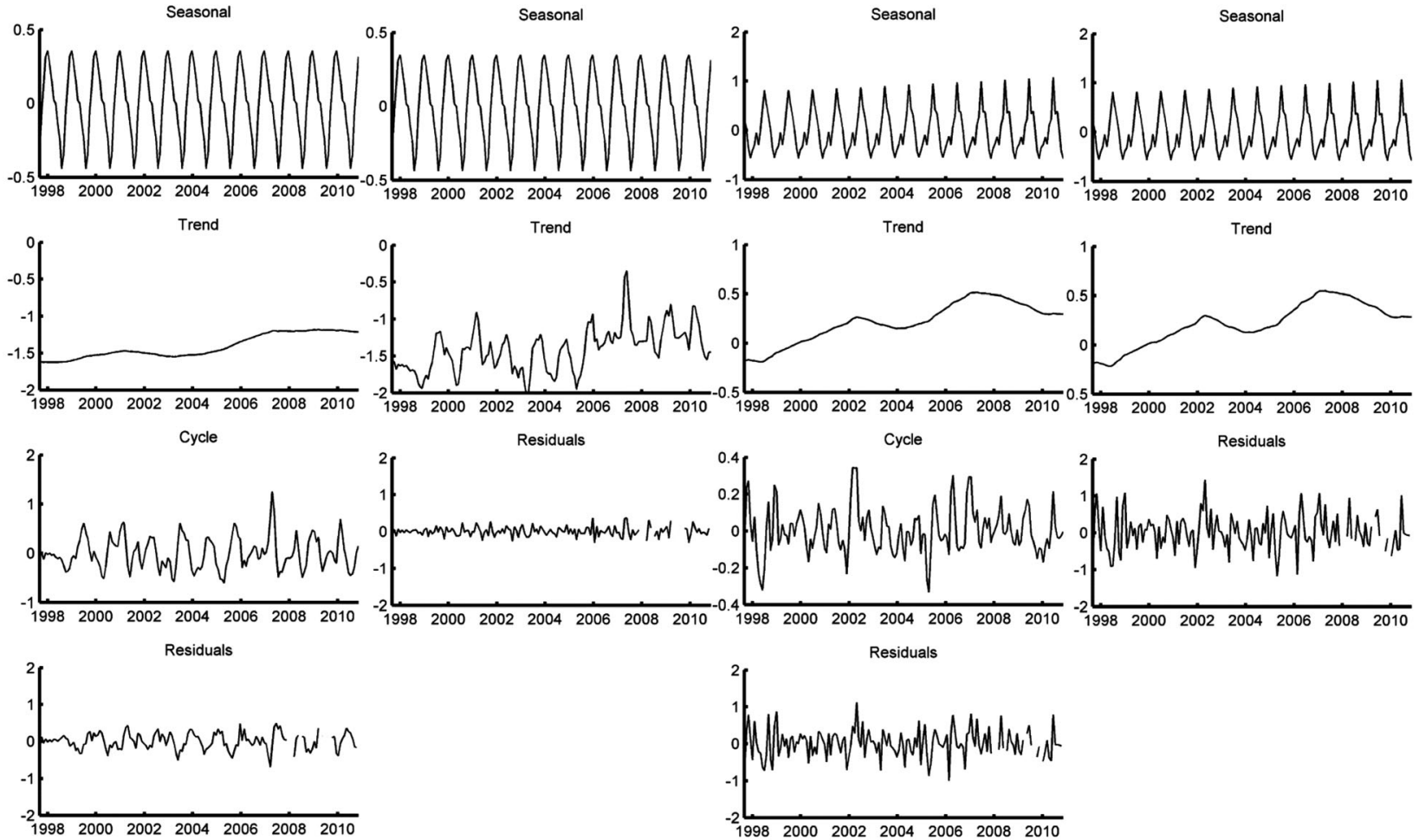

Figure 2. Examples of state-space modeling on satellite-derived chlorophyll time series showing the original $(\log )$ chlorophyll time series and each component from the state-space models, including the slowly varying background trend used in this analysis. Examples are at two individual locations: (a and b) offshore California where model 2 performs better (lowest AIC value) and (c and d) nearshore Oregon where model 1 performs better. The $y$ axis units on all plots is $(\log )$ chlorophyll $\left(\mathrm{mg} \mathrm{m}^{-3}\right)$. AIC values for each model run are shown. 
importance of a trend. The trend represents, or responds to, different processes. Figure $2 b$ shows the effect of model misspecification, where some of the behavior of what is more appropriately a cycle term is picked up by the trend. As the model iterates, each component tries to achieve a balance between interpolating the partial residual and smoothness. If the model is misspecified, the trend is not necessarily smooth. Figures $2 \mathrm{c}$ and $2 \mathrm{~d}$ show a case where the inclusion of a cycle term results in smaller residuals, but the AIC value suggests the addition of another model term does not outweigh this benefit. In both cases, however, the background trends of interest are modeled very similarly and smoothly. Of importance here is the effective removal of higher-frequency components to reveal any slowly varying background trend.

\subsection{Synthesis of State-Space Chlorophyll Trends}

[21] Decomposition of each time series into three (or four) components results in a nonstationary, time-varying trend at each grid location representing low-frequency background changes in the local mean upon which other, higher-frequency variability is superimposed. These higher-frequency components likely contain many signals and structures of interest, but will be dealt with in a separate manuscript. We use two approaches to synthesize dominant patterns within the family of trends over the study area. First, we group the most similar trends using multivariate clustering, map the spatial distribution of the groups and show the temporal evolution of the mean trend vector represented by each. We use k-means clustering, with correlation as the metric of similarity to remove influences of magnitude on cluster membership. Cluster membership is therefore based on similarity of study period changes rather than chlorophyll concentration. Prior to running the kmeans clustering, those trend vectors with extremely low variance $\left(<0.001(\log [\mathrm{CHL}])^{2}\right)$, indicative of essentially no change in trend over the study period, are flagged and isolated. Clustering is performed only on trends that actually change over time. Silhouette analysis, a measure of the mean similarity of individual points to other points within their cluster group compared to those of other cluster groups [e.g., Rousseeuw, 1987], is used to determine the optimal number of clusters to form among trends that do exhibit variance. We tested 3, 4, 5, and 6 cluster groups. Second, the dominant (most coherent) time/space patterns of variability within the trends over the study region are isolated using empirical orthogonal functions (EOFs).

[22] Assessment of the magnitude of overall study period slope described by the trends is done using Sen's slope, a nonparametric estimator that is less sensitive to outliers than linear regression. These have been used effectively on satellite-derived biological data in the California Current previously [Kahru et al., 2009]. Sen's slope calculations on chlorophyll data are done after transforming the log values of the trends back to chlorophyll units. The Mann-Kendall test of significance of these slopes tests the null hypothesis that there is no real slope in the estimated Sen's slope. This hypothesis will be accepted or rejected based on overall slope value compared to the variability within the signal analyzed. On relatively smooth time series, such as the trends resulting from the state-space modeling; therefore, slopes can be statistically significant, even if the absolute magnitude of the actual slope is very weak.

\section{Results and Discussion}

\subsection{Trends in Chlorophyll Concentrations}

[23] Location-specific AIC values over the study region determine which of the two models selected to represent chlorophyll variability provides the better representation of the monthly chlorophyll signal. Mapped AIC differences between the two models (Figure 3) show that at most locations, especially in offshore regions, model 2 performs best. Closer to shore, north of $\sim 34^{\circ} \mathrm{N}$ and widest off northern California and southern Oregon, the simpler model 1 performs better. In areas between these, the two models perform approximately equally. For simplicity, at each location we always use the trend vector produced by the model with lowest AIC. We note that cluster results using trends from either of the models applied systematically across the whole study area (not shown) are not substantially different from the combined results presented below.

[24] Silhouette analyses of trials of k-means clustering of the trends using two to six clusters suggested that four clusters were optimal. K-means assigns every trend vector to a cluster (except the nonvarying trends isolated prior to clustering), with the advantage of providing an overview of the most similar relationships across the whole study area, but the disadvantage that some trend vectors likely cluster weakly to their respective centroid. Figure 4 maps the spatial geography within the study area of each cluster, the mean trend over the study period of the trends that are members of the cluster and the normalized variability within the cluster. Overall, the spatial patterns in the cluster

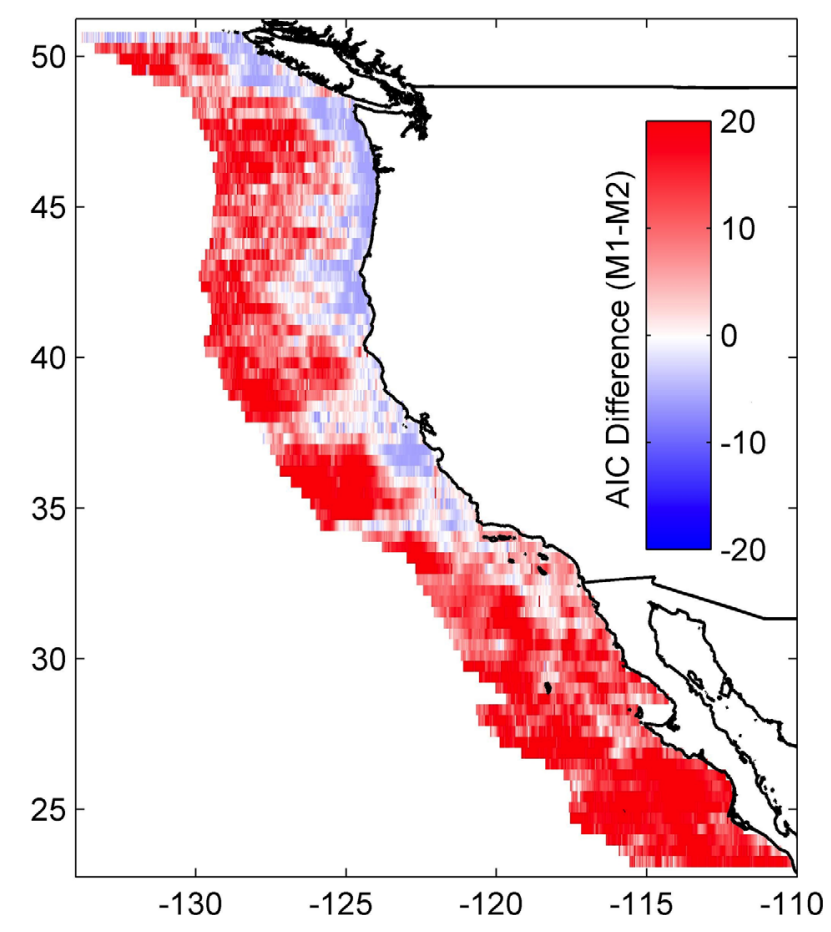

Figure 3. Location-specific AIC differences between the two state-space models over the study area $\left(\mathrm{AIC}_{\text {Model } 1-}\right.$

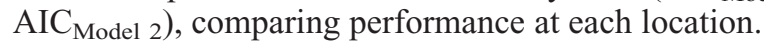



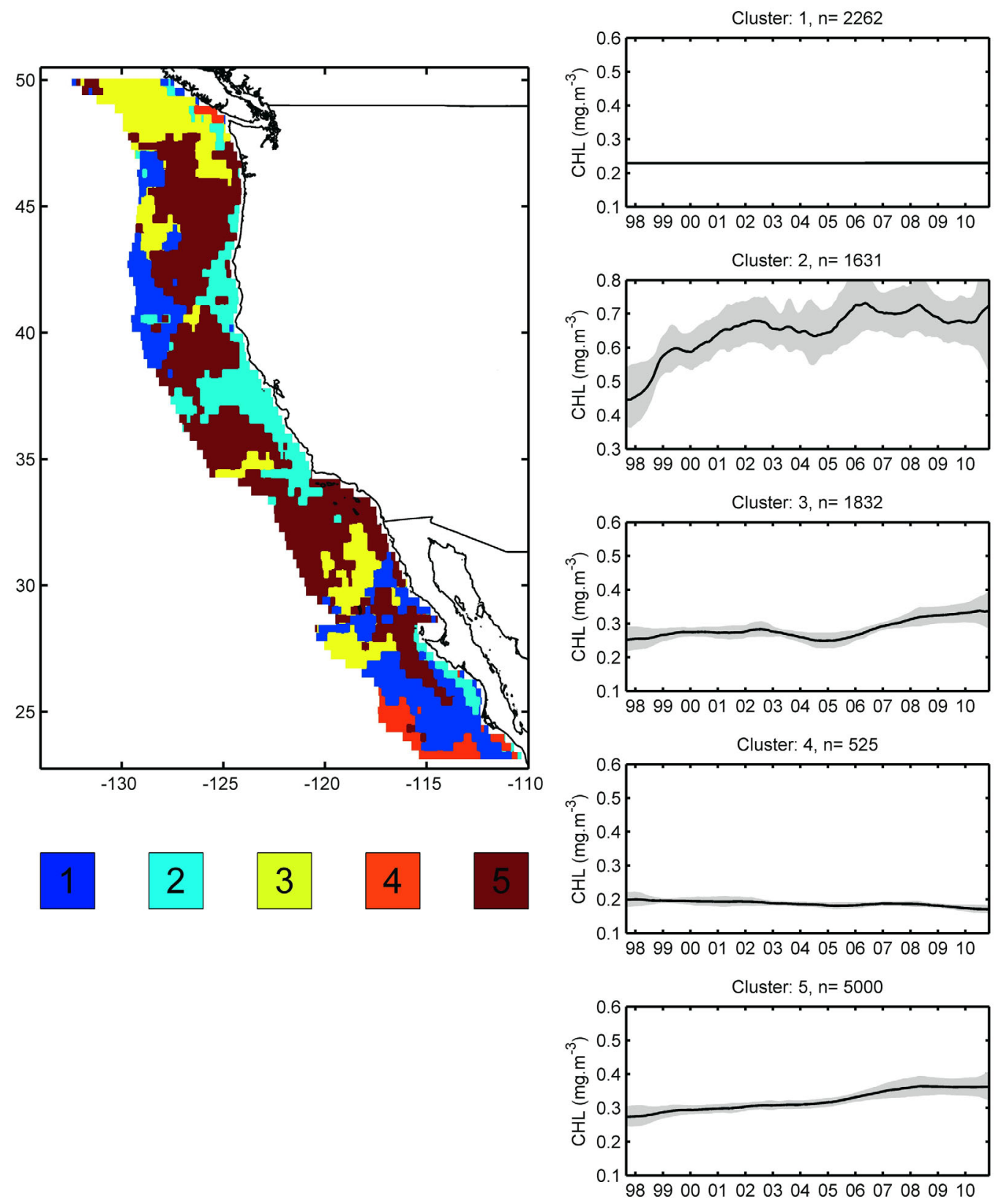

Figure 4. K-means cluster results of the trend from each location showing the mean trend over the 1997-2010 study period within each of the four clusters with their standard deviations, and the spatial pattern associated with these cluster groups. Trends with negligible variance (no discernable change over the study period, blue, labeled as cluster 1, did not enter the multivariate analysis. Mean trends and standard deviations are transformed back into chlorophyll units for display and standard deviations are calculated on trends normalized by subtracting their study-period mean. The number of trend time series making up each cluster is indicated, providing a relative measure of the spatial extent of each over the study area.

results show strong coherence, with similar trends grouping closely in geographic space. Isolated and/or geographically separated locations assigned to the same cluster are relatively few, but result from correlation, used as the distance metric in the clustering. Locations of extremely low temporal variance over the study period, indicative of essentially no change in trend over the years examined (labeled cluster 1 ), occupy $20 \%$ of the study area and are centered in farthest offshore regions between $38^{\circ}$ and $47^{\circ} \mathrm{N}$ and also in a region just seaward of the coastal upwelling zone off Baja California, primarily south of $\sim 27^{\circ} \mathrm{N}$. Chlorophyll variability in these regions was entirely within the seasonal, cyclic, and/or irregular portions of the state-space models. Within Cluster 2, the mean trend has lowest chlorophyll concentrations at the beginning of the record during the El Niño period. These rise strongly in mid-1998 to $\sim 0.6 \mathrm{mg} \mathrm{m}^{-3}$ and then continues an increasing trend but with a smaller slope to the end of the study period, with localized peaks in 2002 , 
2006, and 2008. The spatial pattern indicates that this cluster represents the coastal upwelling region along most of southern Oregon and northern-central California coasts, including a coastal region extending along southern Baja California south of Punta Eugenia. The region extends farthest seaward at $\sim 37^{\circ} \mathrm{N}$ off central California but is closer to the coast in both its northern and southern extremes. This cluster represents $14 \%$ of the study area and has the largest within-cluster variance. Cluster 3 has overall lower mean values than cluster 2 , is relatively unchanging from 1997 to early 2005 , but thereafter increases steadily to the end of the study period. This temporal pattern represents $16 \%$ of the study area, is present at a number of offshore locations, but is most strongly represented in two regions, one off Washington and British Columbia in areas away from the immediate coast, and the other in offshore areas of northern Baja California. Of the five cluster means, Cluster 4 has the lowest overall means, remaining less than $0.2 \mathrm{mg} \mathrm{m}^{-3}$, has the smallest within-cluster variance, represents the smallest spatial area (5\% of the study area), and is the only cluster mean that shows an overall decreasing trend. Mean values decrease steadily from 1997 until the end of the time series. Geographically, trends within this cluster represent the most southerly waters of our study area and are primarily seaward of the coastal upwelling region off southern Baja California, south of $\sim 25^{\circ} \mathrm{N}$. Cluster 5 is characterized by lowest values in 1997-1998 and a steadily increasing trend over the study period. This increasing trend is weak from the beginning of the record until 2005, increases in the period 2005-2008, but then it weakens again after early 2008. This trend pattern represents the largest portion of the study area (44\%). Geographically, Cluster 5 maps primarily offshore regions, between the coastal upwelling region and farthest offshore regions between $\sim 37^{\circ}$ and $48^{\circ} \mathrm{N}$, and off central Baja California, but extending completely to the western edge of the study area between $30^{\circ}$ and $36^{\circ} \mathrm{N}$ and intruding completely to the coast in the southern California Bight and off northern Baja California.

[25] Dominant patterns of the background trends in chlorophyll concentration that result from the state-space analyses across the entire study area are summarized as an empirical orthogonal function (EOF) decomposition (Figure 5) that isolates the dominant modes of coherent time/ space variability. Together, the first three modes summarize the largest space and time signals, capture important location-specific trend variability less clearly evident in the clusters, and explain $>80 \%$ of the total variance. The first mode $(65.3 \%$ of the total trend variability) has a strongly increasing overall temporal trend (Figure 5a). The time series is characterized by lowest values in the beginning of the study period during 1997-1998 that rise strongly during 1998 , followed by a period of weaker, but still increasing trend from 1999 into early 2005. Thereafter, the strength of this mode increases rapidly over the period 2005-2008, before becoming more stable again in the last three years. The space pattern shows this temporal pattern to be most strongly expressed in regions offshore of central and southern California, slightly weaker right in the southern California Bight. It is also strong in coastal areas of the Pacific Northwest and away from the shelf off British Columbia. Weakest areas are south of $\sim 30^{\circ} \mathrm{N}$ off Baja California and in the regions farthest offshore between $\sim 38^{\circ}$ and $47^{\circ} \mathrm{N}$. In the most southern portions of the study area offshore of southern Baja California, and in a narrow coastal strip off British Columbia, the space pattern is weakly negative, indicative of a decreasing trend and a maximum in 19971998. The second mode $(10.2 \%$ of total variance, Figure 5b) modifies the previous temporal pattern primarily by adjusting chlorophyll values in the 1997-1998 period (negative), in 2004-2006 (positive), and in 2008-2009 (negative). The space pattern shows this modification is strongest and positive along the Oregon and north-central California coastal region, strongest off central California. The inverse of this modification (increasing chlorophyll values in the 1997-1998 and 2008-2009 periods) is strongest off British Columbia and Washington. The primary impact of the third mode $(8.3 \%$ of total variance, Figure $5 \mathrm{c})$ is to strengthen differences in values between the 1997-1998 and the 2000-2003 periods. This mode contributes most strongly in a positive manner off British Columbia and in isolated coastal regions along Oregon and northern California, and in a negative manner (weakening 1997-1998 and 20002003 differences) off southern California, including the entire southern California Bight.

[26] Estimates of the linear slope in the 13 year trend in chlorophyll concentration represented by means of the cluster groups and EOF mode 1 are summarized as their respective Sen's slope (Table 1), calculated after transforming each of their respective vectors back into chlorophyll units. All four of the cluster groups (2-5) that entered the analysis have statistically significant slopes over the study period. The strongest positive slope is in cluster 2 representing the California Current coastal upwelling region between central Oregon and Point Conception. The slope is positive, but weaker, in clusters 3 and 5. The slope is weak and negative in cluster 4. For context, these slopes are also expressed as a percentage of the 13 year mean chlorophyll concentration calculated over the spatial domain of each cluster (Table 1). The slope of the first mode of the EOF decomposition is also strongly positive.

[27] Location-specific Sen's slopes of each trend in the data set (Figure 6a) map the spatial pattern in the strength of change in chlorophyll concentrations over the study period in more detail than those evident in the cluster means and the EOF decomposition, at the expense of showing the temporal structure of the local trend. Although many of the slopes are weak, removal of the higher-frequency seasonal, cycle, and irregular components in the state-space modeling results in relatively smooth trends (e.g., Figure 2) and most $(96.5 \%)$ have statistically significant slopes (Figure 6a). Slopes are positive throughout most of the study region, with strong spatial coherence, maximum near the coast north of $\sim 32^{\circ} \mathrm{N}$, and weakest in furthest offshore and southernmost areas south of $\sim 32^{\circ} \mathrm{N}$. Maximum slopes $\left(>0.2 \mathrm{mg} \mathrm{m}^{-3}\right.$ decade $\left.^{-1}\right)$ are evident in coastal regions off central California and along the coasts of Washington and north to central Oregon. Two relatively small regions of negative slope are evident, one along the coast of southern Baja California that extends offshore but becomes much weaker, and a small region on the southern British Columbia shelf. Along other coastal regions, overall positive slopes are weak off northern Vancouver Island, immediately adjacent to the coast off northern California and 


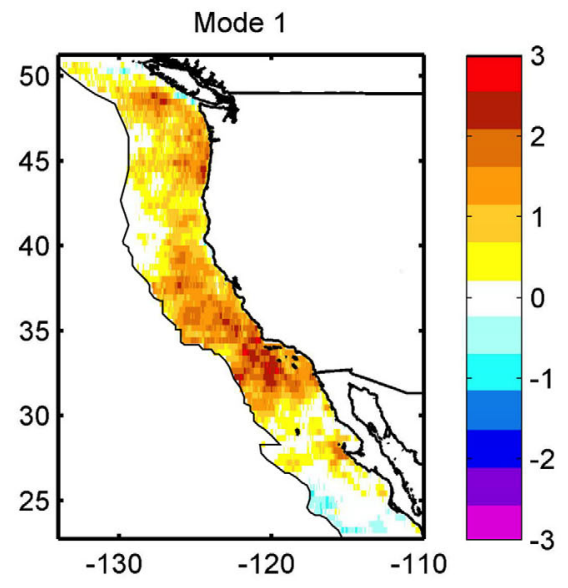

a)
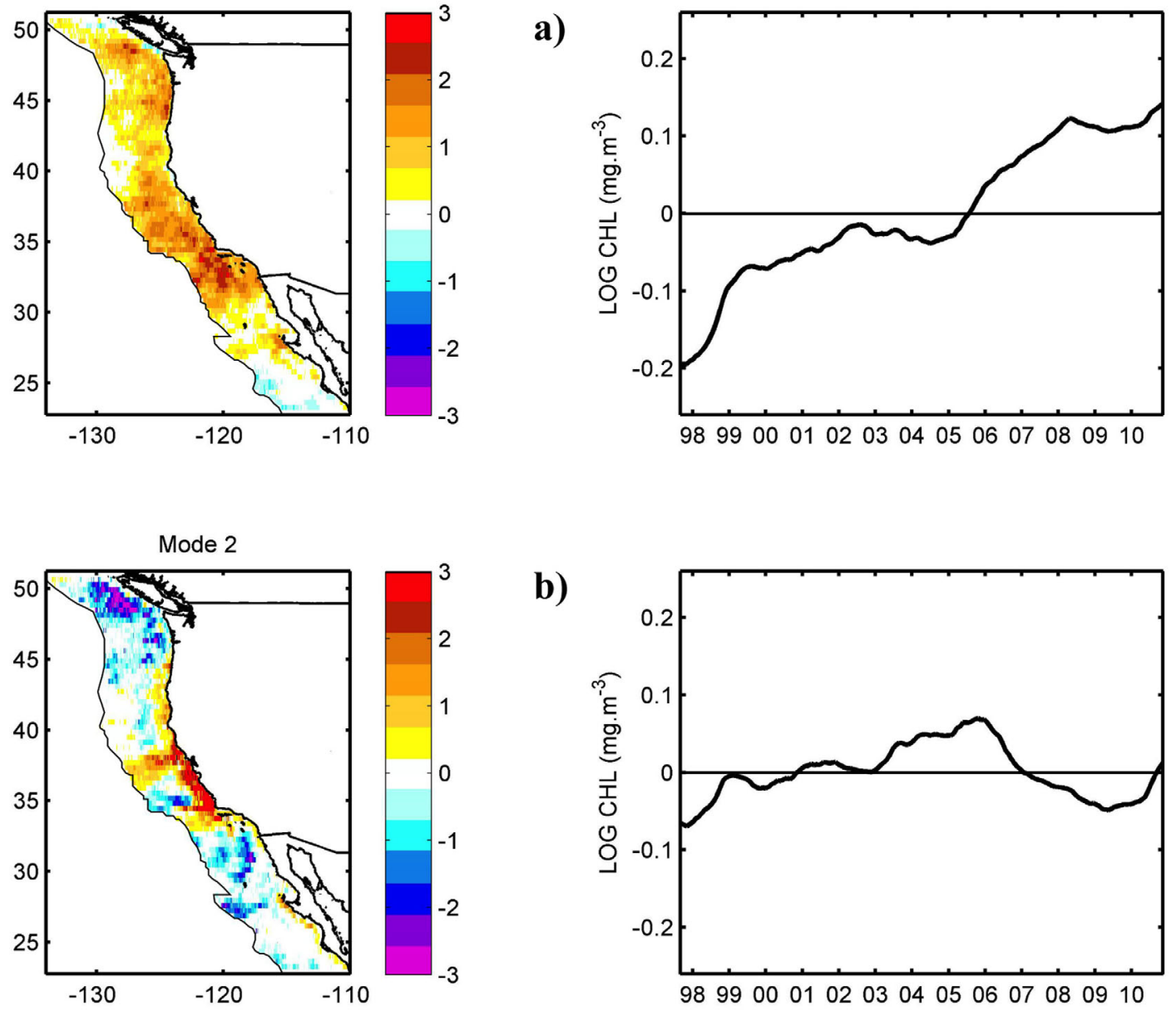

b)

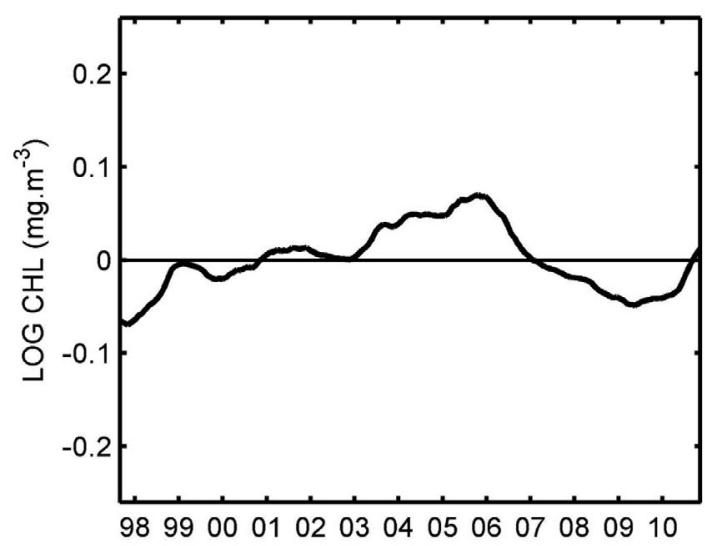

Mode 3

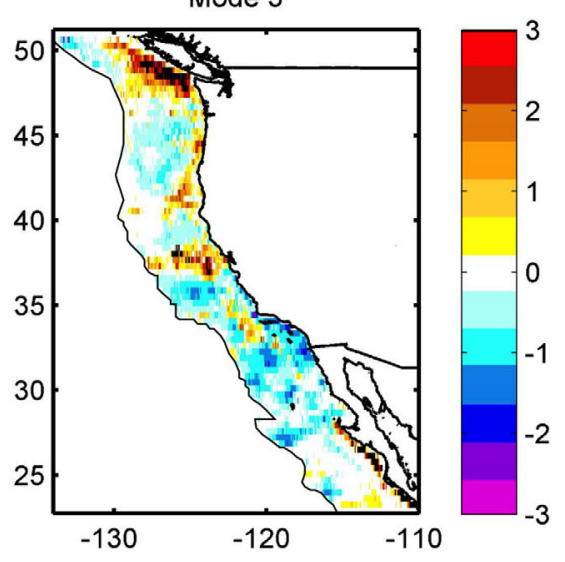

c)

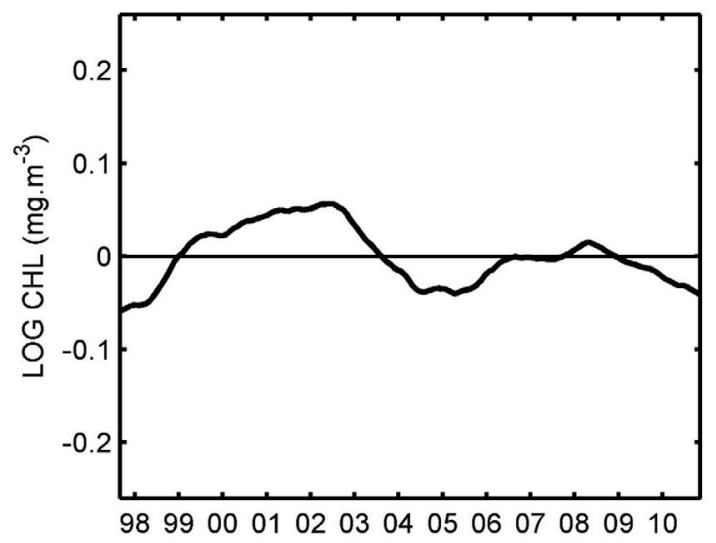

Figure 5. The first three modes of an EOF decomposition of the state-space trends of chlorophyll over the study area showing the space pattern of weightings of each mode and their respective amplitude time series.

southern Oregon and along the northern Baja California coast. Statistical significance, however, is not the same as ecological significance. Although the state-space models successfully identify and isolate trends, the weakest slopes are not necessarily important from a trophic perspective, except over a longer period than that studied here. To provide perspective on this and also to place the magnitude of the slopes into local context, the slopes of the trends at each location are expressed as a percentage of the local 13 year mean chlorophyll concentration (Figure 6b). Between $\sim 30^{\circ} \mathrm{N}$ and $49^{\circ} \mathrm{N}$ the positive trends amount to $>20 \%$ change per decade over a relatively large region, maximum 
Table 1. Sen's Slope of 13 Year Chlorophyll Trend Patterns

\begin{tabular}{lcc}
\hline Time Series & $\begin{array}{c}\text { Slope } \\
\left(\mathrm{mg} \mathrm{m}^{-3} \text { decade }^{-1}\right)\end{array}$ & $\begin{array}{c}\text { Slope }(\% \text { of 13 year } \\
\text { mean decade }\end{array}$ \\
\hline Cluster 1 & 0 & \\
Cluster 2 & $0.118^{\mathrm{a}}$ & $13.6 \%$ \\
Cluster 3 & $0.058^{\mathrm{a}}$ & $14.4 \%$ \\
Cluster 4 & $-0.019^{\mathrm{a}}$ & $4.5 \%$ \\
Cluster 5 & $0.073^{\mathrm{a}}$ & $17.2 \%$ \\
EOF mode 1 & $0.228^{\mathrm{a}}$ & \\
\hline
\end{tabular}

${ }^{\mathrm{a}}$ Significant at $95 \%$.

( $>40 \%$ per decade) in regions centered 200-400 km offshore of central and southern California. In regions south of $30^{\circ} \mathrm{N}$, offshore regions north of $\sim 38^{\circ} \mathrm{N}$ and coastal upwelling regions off northern California, the slopes are $<10 \%$ of the local chlorophyll concentration per decade.

\subsection{Discussion of Chlorophyll Trends}

[28] The state-space models isolate the background nonlinear trend in chlorophyll concentrations at each location from shorter time scale variability. Two observations are initially apparent. First, the space pattern presenting the most effective model of the local chlorophyll time series (Figure 3 ) has geography and boundaries familiar from previous work [e.g., Mackas, 2006]. The simpler model (Model 1) implies chlorophyll variability dominated by fewer processes and is characteristic of the coastal, strongly seasonal wind-driven upwelling region north of Point Conception. Better fit of more complicated models (Model 2) implies more, or more equally effective, sources of variability, characteristic of the lower chlorophyll concentrations in more oligotrophic offshore regions [Kahru and Mitchell, 2001; Legaard and Thomas, 2006]. The Southern California Bight is similar to offshore regions and Point Conception is a boundary, consistent with well-established physical forcing and biological patterns [e.g., Hickey, 1998; Mackas, 2006]. The Baja California coastal upwelling region is also best modeled by the more complex model, likely reflecting increased interactions between weaker, but more persistent upwelling and strong solar heating [Espinosa-Carreon et al., 2004]. Second, it is evident (Figures 4 and 5) that reduced chlorophyll values in many regions that characterize the 1997-1998 El Niño period [Chavez et al., 2002; Thomas et al., 2009], a result of an increased depth of the warm upper layer, are persistent enough to remain in the trend component. Concentrations during this period are the lowest of the entire time series for Cluster 2 and are evident but weaker in Clusters 3 and 5. Between them, these clusters occupy the coastal regions over the entire latitudinal range of the California Current system and extend offshore to the western edge of the study area at most latitudes north of $\sim 28^{\circ} \mathrm{N}$. In contrast, concentrations during the $\mathrm{El}$ Niño period in Cluster 4 are the maximum in this time series. These elevated chlorophyll values, observed off Baja California, are consistent with previous observations [Kahru and Mitchell, 2000] and are hypothesized to be a bloom of nitrogen-fixing cyanobacteria. These authors observed this bloom as positive anomalies in 3 year time series. The data shown here indicate that elevated El Niño-period chlorophyll concentrations in this region contribute to the overall background trend for the 13 year time series.

[29] The state-space modeling shows a background trend of increasing chlorophyll concentrations throughout most
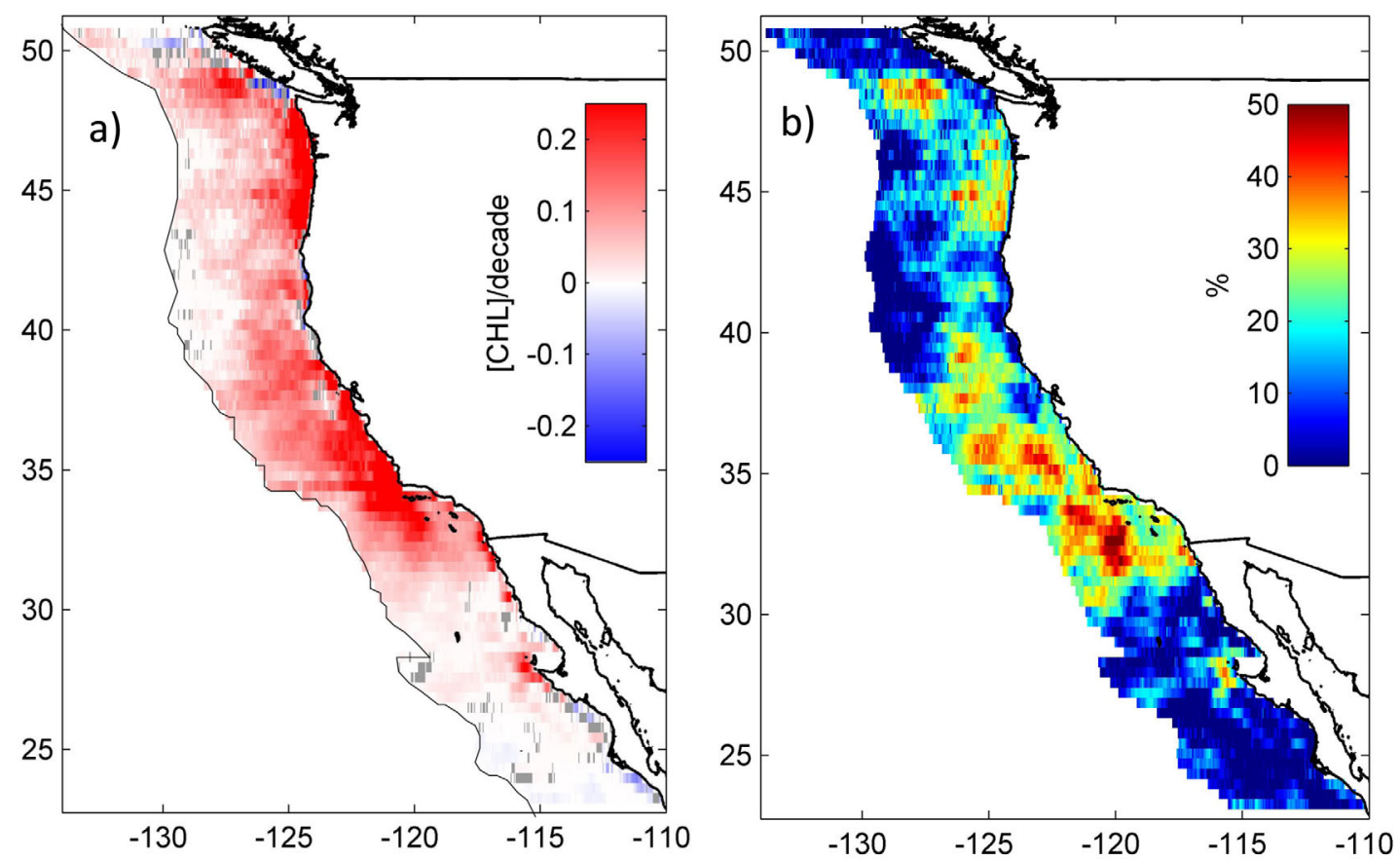

Figure 6. (a) Sen's slopes $\left(\mathrm{mg} \mathrm{m}^{-3} \mathrm{decade}^{-1}\right)$ of the chlorophyll trend at each location over the study region. Gray indicates locations where the Mann-Kendall test of slope significance failed to exceed $95 \%$ (3.5\% of the region). Each trend vector was transformed back to chlorophyll units prior to slope calculation. (b) Sen's slopes at each location expressed as a percentage of the local 13 year mean chlorophyll concentration. 
of the California Current region over the SeaWiFS mission period (Figure 6). Of interest is the degree to which the positive slopes in chlorophyll are influenced by the El Niño period over the first 8-12 months of the study period. We removed this period in the time series at each location by eliminating the first 12 months and then recalculated the two state-space models for the remaining period (September 1998-December 2010). After selecting the lowest AIC score at each location, Sen's slope was calculated for the trend at each location. Results (Figure 7) show that the number of nonsignificant slopes remains almost unchanged (3.5\% versus $3.2 \%$ ) compared to the full time series, a general weakening of all slopes, but overall strong similarity in the spatial patterns of positive slope evident in the entire time series (Figure 6). Among the most notable differences are stronger negative slopes along the Baja California coastal upwelling region south of Punta Eugenia and a number of locations that shift from weak positive slopes to weak negative slopes. Strong positive trends are still present along the Washington and Oregon coastal upwelling regions, with slopes that remain very similar. Overall, these data suggest that while the El Niño period contributes to the magnitude of the positive trends over most of the California Current region during our study period, increasing chlorophyll concentrations are evident, and significant,

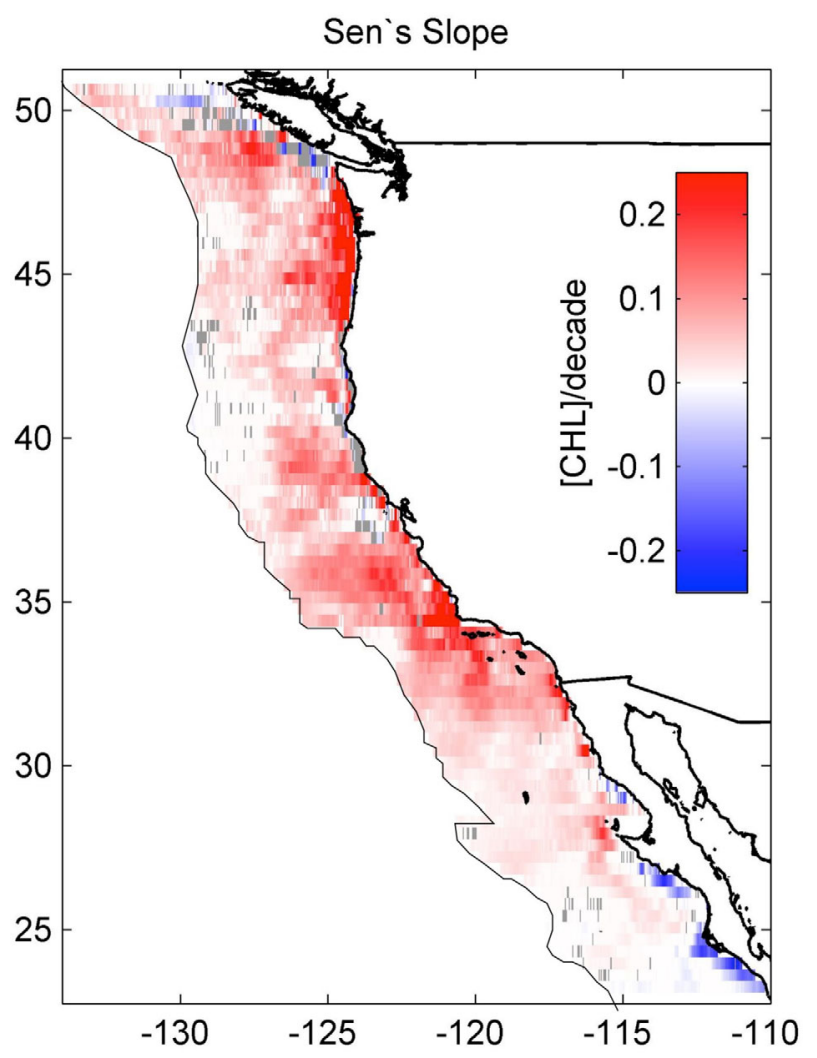

Figure 7. Sen's slopes $\left(\mathrm{mg} \mathrm{m}^{-3} \mathrm{decade}^{-1}\right)$ of the chlorophyll trend without the El Niño period (September 1998December 2010) at each location over the study region. Gray indicates locations where the Mann-Kendall test of slope significance failed to exceed $95 \%$ (3.2\% of the region). Each trend vector was transformed back to chlorophyll units prior to slope calculation. even without this event. This view is consistent with that calculated for primary productivity [Kahru et al., 2009] and of multidecadal increasing chlorophyll in the California Current region between $30^{\circ}$ and $34^{\circ} \mathrm{N}$ measured in ship data [Aksnes and Oman, 2009].

[30] Comparisons of the increasing trends in chlorophyll concentration evident in the results here and their respective spatial patterns in the California Current can be made to previous views to highlight differences uncovered by the state-space modeling approach. Kahru et al. [2009] show increasing primary production calculated from satellite data in the coastal region throughout the California Current over the September 1997-2007 period, but their region of significant trends is more restricted to the coast (within $\sim 100 \mathrm{~km}$ ) than patterns evident in Figures 5 and 6. Extending this analysis to include multiple satellite instruments, trends in chlorophyll anomalies over the 1996-2011 period [Kahru et al., 2012] show statistically significant positive trends throughout the Southern California Bight and off central California extending as far north as $\sim 38^{\circ} \mathrm{N}$ as isolated patches, and a broad region of negative trends south of $\sim 25^{\circ} \mathrm{N}$ off Baja California. Other regions, most notably off northern California, Oregon, and Washington did not show statistically significant trends. The differences between these views and that offered by the state-space models presented here is due to our removal of nonstationary seasonal signals and other higher-frequency variability that may mask, or at least reduce the statistical significance of, background trends. Each approach offers complimentary views of the same patterns. Relatively coarse spatial resolution global views of 10 year chlorophyll trends from satellite data [Vantrepotte and Melon, 2011], using a technique that also separates out the nonstationary higherfrequency components, portray the entire California Current region as increasing. In their parallel analyses of simple anomaly chlorophyll time series, such a positive trend was only evident in isolated patches in the California Current. Also as part of a global analysis, an increase in chlorophyll concentration is evident over most of the California Current region between 1979-1983 and 1998-2002 [Antoine et al., 2005]. Their data also shows a decline in the Baja California region. Increasing chlorophyll in California coastal regions are consistent with in situ measured chlorophyll trends over a 30 year period in the San Francisco Bay region [Cloern et al., 2010] and in very nearshore waters of the Southern California Bight [Kim et al., 2009]. Our results are also consistent with field data over the greater Southern California Bight region $\left(\sim 30^{\circ}-34^{\circ} \mathrm{N}\right)$, which show the euphotic zone and nitracline depth has decreased, associated with increases in surface chlorophyll concentration and decreases in Secchi depth over the past 40 years [Aksnes and Ohman, 2009].

\subsection{Chlorophyll Trend Relationships to Forcing}

[31] Increasing chlorophyll concentrations in planktonic marine systems suggest increases in nutrient flux into the euphotic zone and/or changes in grazing pressure. In productive EBC systems characterized by wind-driven coastal upwelling, one explanation for the positive chlorophyll concentration trends is increased wind-driven upwelling, consistent with Bakun [1990]. To test this, we applied state-space modeling to time series of monthly mean 

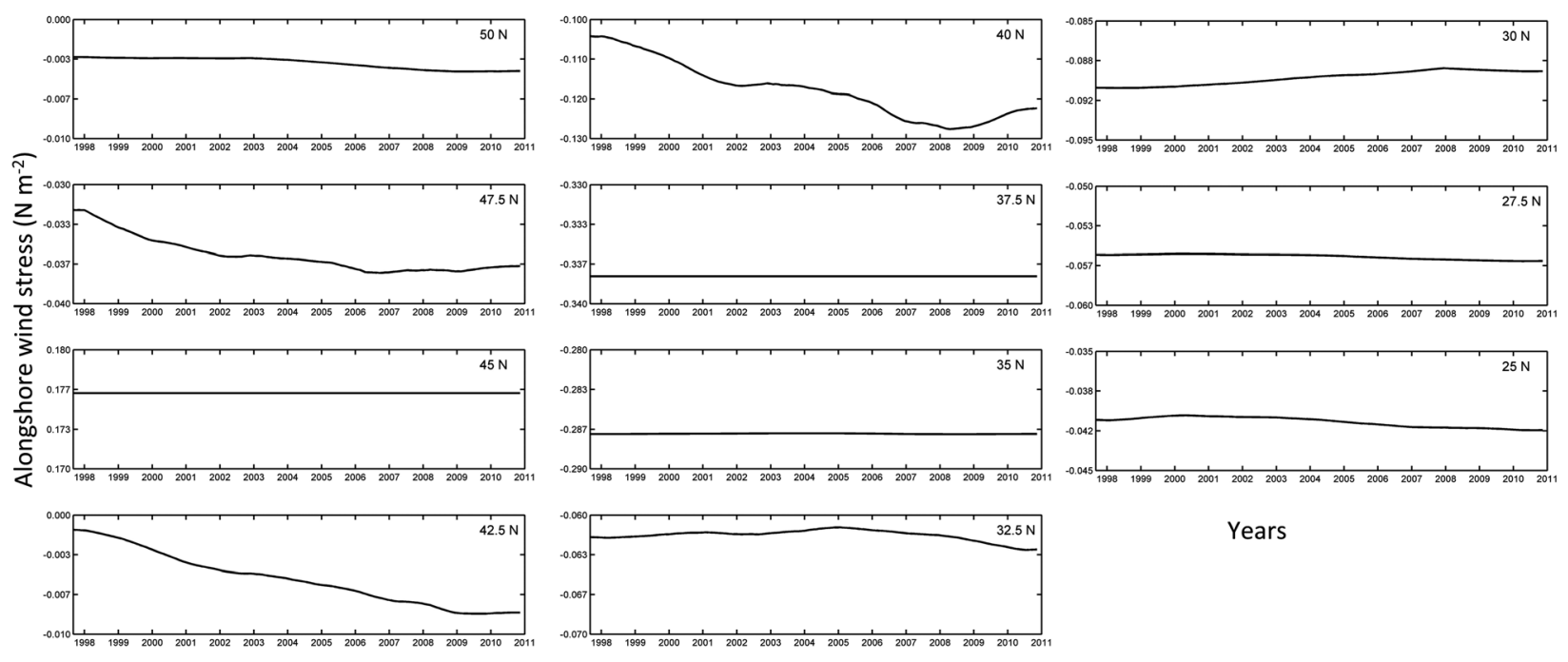

Figure 8. Trend components of state-space models of alongshore wind stress over the study period at coastal locations for 11 different latitudes. Note: the scaling is the same (range of $0.01 \mathrm{~N} \mathrm{~m}^{-2}$ ) for all panels except $40^{\circ} \mathrm{N}$ (range of $0.03 \mathrm{~N} \mathrm{~m}^{-2}$ ).

alongshore wind stress over the SeaWiFS mission period. Examination of residuals properties and AIC values showed that the most appropriate model was the most parsimonious (Model 1 in section 2). As with the chlorophyll, the models separate background trends from nonstationary seasonal signals and other high-frequency ( $\sim$ independent, normally distributed, zero mean) variability. We examine trends at a series of 11 coastal locations over the latitudinal extent of the study area (Figure 1). The trends of alongshore wind stress that result from the modeling (Figure 8) are partially consistent with the hypothesis of increased upwelling-favorable wind forcing. At most locations, there is a significant negative trend over the time series (increasing equatorward wind stress). At many locations, however, this trend is weak enough $\left(<0.0001 \mathrm{~N} \mathrm{~m}^{-2}\right.$ decade $\left.^{-1}\right)$ to be of questionable importance. Sen's slopes calculated for these winds (Table 2) show increased upwelling trends are strongest $\left(-0.0184\right.$ and $-0.0055 \mathrm{~N} \mathrm{~m}^{-2}$ decade $\left.^{-1}\right)$ off northern California $\left(40^{\circ} \mathrm{N}\right.$ and $\left.42.5^{\circ} \mathrm{N}\right)$, the region of climatological maximum in summer upwelling-favorable wind

Table 2. Sen's Slope of State-Space Trend in 13 Years of Alongshore Wind Stress

\begin{tabular}{|c|c|c|}
\hline Latitude & $\begin{array}{c}\text { Slope }\left(\mathrm{N} \mathrm{m}^{-2}\right. \\
\left.\text { decade }^{-1}\right)\end{array}$ & $\begin{array}{l}\text { Slope (\% of } 13 \text { year } \\
\text { mean decade }{ }^{-1} \text { ) }\end{array}$ \\
\hline $50^{\circ} \mathrm{N}$ & $-0.0011^{\mathrm{a}}$ & $-30.7 \%$ \\
\hline $47.5^{\circ} \mathrm{N}$ & $-0.0031^{\mathrm{a}}$ & $-8.5 \%$ \\
\hline $45^{\circ} \mathrm{N}$ & $-0.0000^{\mathrm{a}}$ & $-0 \%$ \\
\hline $42.5^{\circ} \mathrm{N}$ & $-0.0055^{\mathrm{a}}$ & $-102.0 \%$ \\
\hline $40^{\circ} \mathrm{N}$ & $-0.0184^{\mathrm{a}}$ & $-15.7 \%$ \\
\hline $37.5^{\circ} \mathrm{N}$ & $-0.0000^{\mathrm{a}}$ & $-0 \%$ \\
\hline $35^{\circ} \mathrm{N}$ & $-0.0000^{\mathrm{a}}$ & $-0 \%$ \\
\hline $32.5^{\circ} \mathrm{N}$ & -0.0002 & $-0.3 \%$ \\
\hline $30^{\circ} \mathrm{N}$ & $0.0016^{\mathrm{a}}$ & $1.7 \%$ \\
\hline $27.5^{\circ} \mathrm{N}$ & $-0.0005^{\mathrm{a}}$ & $-1.0 \%$ \\
\hline $25^{\circ} \mathrm{N}$ & $-0.0011^{\mathrm{a}}$ & $-2.6 \%$ \\
\hline
\end{tabular}

${ }^{\text {a }}$ Significant at $95 \%$, magnitudes less than four significant figures are entered as zero but the sign retained. stress [Bakun and Nelson, 1991]. Other regions have much weaker, but still statistically significant negative Sen's slopes over the study period. The only region of positive trend (weakening upwelling) is on the northern Baja California coast, at $30^{\circ} \mathrm{N}$. The overall picture is of a weak increasing trend in upwelling-favorable winds over most California Current coastal regions over the study period. This view is consistent with an increasing trend in upwelling off central California in 1982-2008 [Garcia-Reyes and Largier, 2010], a period that overlaps that examined here, and over longer period (1946-1990) that does not overlap ours [Schwing and Mendelssohn, 1997]. Differences in the strength of the trends between these studies and those shown here are at least partially due to our inclusion of all months in estimating the overall trends, compared to calculations over just the summer upwelling period in the earlier studies. Our results are also consistent with an increasing trend in annual cumulative upwelling off southern British Columbia over the past four decades reported by Foreman et al. [2011].

[32] Within EBC upwelling regions, to a first approximation, increasing nutrient flux into surface waters to sustain increasing chlorophyll concentrations would be associated with decreased SST. We used state-space models to examine background trends in SST over the study period at six latitudes at locations adjacent to the coast in upwelling zones and at the western edge of our study area (Figure 1) for consistency with our observed chlorophyll trends. The most appropriate model separated the SST monthly time series into background trend, seasonal, cycle, and error terms (model 2, in section 2). At coastal locations, trends (Figure 9) show overall decreasing SST, consistent with increased upwelling. Although all are statistically significant, these trends are weak/negligible south of $44^{\circ} \mathrm{N}$. Sen's slopes (Table 3) are maximum off the Pacific Northwest (stronger than $-0.4^{\circ} \mathrm{C}$ decade $^{-1}$ ). Those south of $44^{\circ} \mathrm{N}$ are weaker than $-0.08^{\circ} \mathrm{C}$ decade $^{-1}$. SST trends at all offshore locations are weak (Figure 9) with Sen's slopes all $<0.08^{\circ} \mathrm{C} \mathrm{decade}^{-1}$ ) and of inconsistent signs (Table 3 ). For 

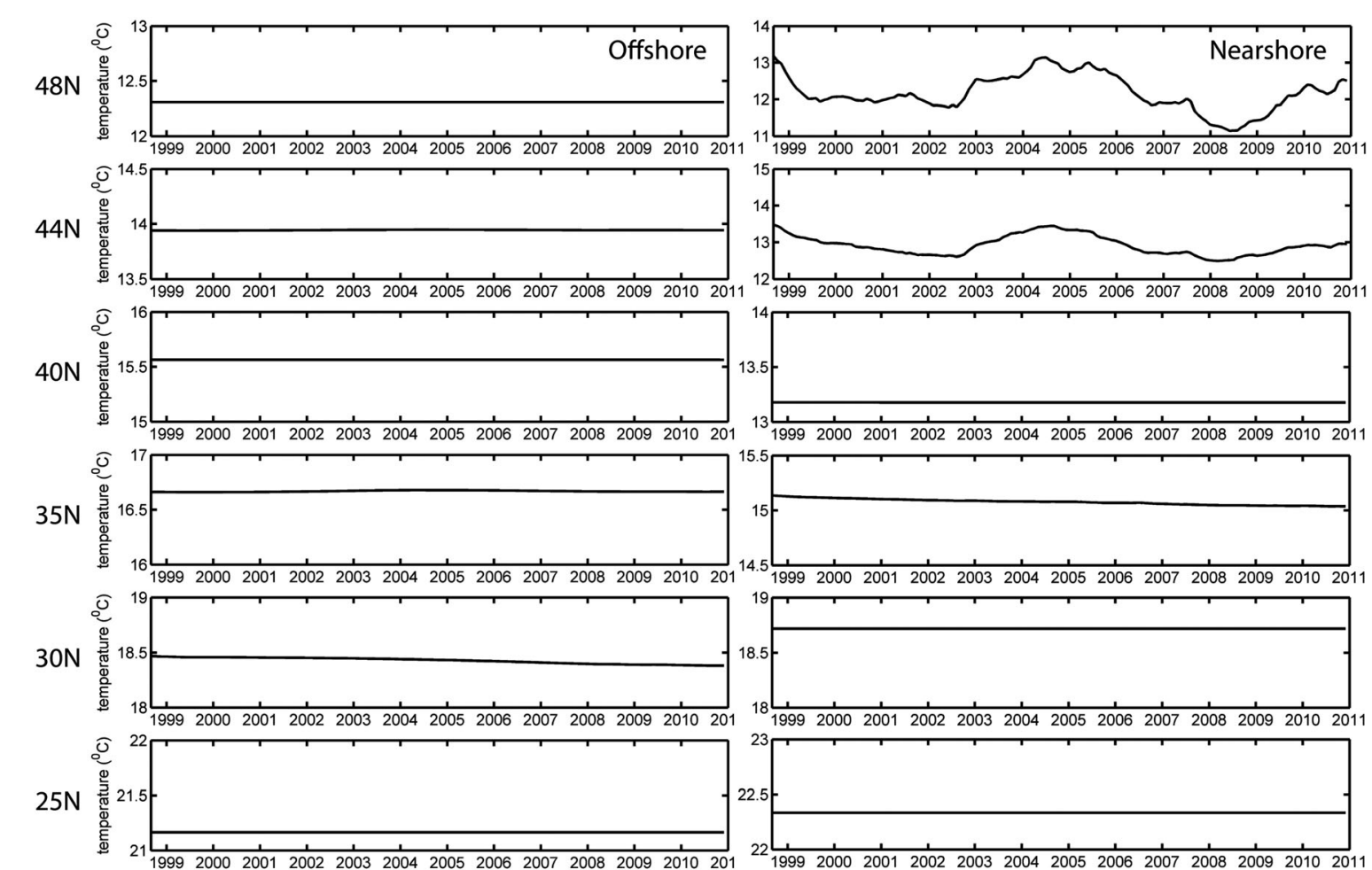

Figure 9. Trend components of state-space models of SST over the study period for six latitudes, at $600 \mathrm{~km}$ offshore and coastal locations. Note: the scaling differs between the northernmost two nearshore (right) locations (range of $3.0^{\circ} \mathrm{C}$ ) and all others (range of $1.0^{\circ} \mathrm{C}$ ).

the coastal region cooling off the Pacific Northwest, the trend time series suggest that a significant contribution to this increase is warm SSTs during the initial period of El Niño conditions. We recalculated the SST state-space models without the first year of data (not shown) and the two Pacific Northwest slopes remain negative but are reduced in magnitude. The overall picture from SST variability over the study period is of decreasing coastal temperatures off the Pacific Northwest, largely due to the warm SSTs of the initial El Niño period, but weak SST decreases over the rest of the coastal California Current. There is little evidence in these SST data of trends in locations away from shore. The slopes calculated here for the 1997-2010 period provide some spatial context to those provided by Belkin [2009] averaged over the entire California Current system of 0.0 to $-0.1^{\circ} \mathrm{C}$ for a 25 year period ending in 2006 , or a

Table 3. Sen's Slope of State-Space Trend in 13 Years of SST

\begin{tabular}{lcc}
\hline & \multicolumn{2}{c}{ Sen's Slope $^{\mathrm{a}}\left({ }^{\circ} \mathrm{C}\right.$ decade $\left.^{-1}\right)$} \\
\cline { 2 - 3 } Latitude & \multicolumn{2}{c}{$\begin{array}{c}\text { Offshore } \\
\text { Offor }\end{array}$} \\
\hline $48^{\circ} \mathrm{N}$ & -0.0000 & Coast \\
$44^{\circ} \mathrm{N}$ & 0.0031 & -0.6680 \\
$40^{\circ} \mathrm{N}$ & 0.0000 & -0.4484 \\
$35^{\circ} \mathrm{N}$ & 0.0033 & -0.0008 \\
$30^{\circ} \mathrm{N}$ & -0.0745 & -0.0766 \\
$25^{\circ} \mathrm{N}$ & -0.0002 & -0.0003 \\
\hline
\end{tabular}

${ }^{\text {a }}$ All are significant at $95 \%$, magnitudes less than four significant figures are entered as zero but the sign retained. maximum of $\sim-0.04^{\circ} \mathrm{C}$ decade ${ }^{-1}$. The trends presented here cover a period after the 45 year time window ending in 1990 analyzed by Mendelssohn and Schwing [2002], but suggest similar latitudinal differences in slope. Their analysis showed increasing SST trends off Baja California of $0.03-0.16^{\circ} \mathrm{C}$ decade $^{-1}$ and a switch to decreasing trends north of $\sim 35^{\circ} \mathrm{N}$, with slopes of -0.02 to $-0.23^{\circ} \mathrm{C}$ deca$\mathrm{de}^{-1}$. A notable difference is that their maximum negative slopes were off northern California, south of the maximum trends shown here, but consistent with locations of increasing upwelling-favorable wind stress (Figure 7).

[33] Global views of chlorophyll interannual variability show a linkage between overall California Current chlorophyll and basinscale climate-related forcing indices such as the Multivariate El Niño Index (MEI) [Martinez et al., 2009] and more detailed views focused on the California Current suggest regional differences in the magnitude of the chlorophyll response to such signals [e.g., Thomas et al., 2012]. Relationships between the trend vectors at each location and two such climate-related signals, as simple correlations (Figure 10), provide the spatial footprint of each on the background trends in chlorophyll concentration presented by the state-space models. Correlation does not imply causality and the statistical significance of the actual correlations is questionable due to relatively long decorrelation time scales in the chlorophyll trends and the short time series available. Comparison of the two time series (Figures 10c-10e), however, suggests many similarities in their time-varying structure resulting in strong correlations over relatively large areas (Figures $10 \mathrm{a}$ and $10 \mathrm{~b}$ ). The North Pacific Gyre Oscillation [Di Lorenzo et al., 2008], 


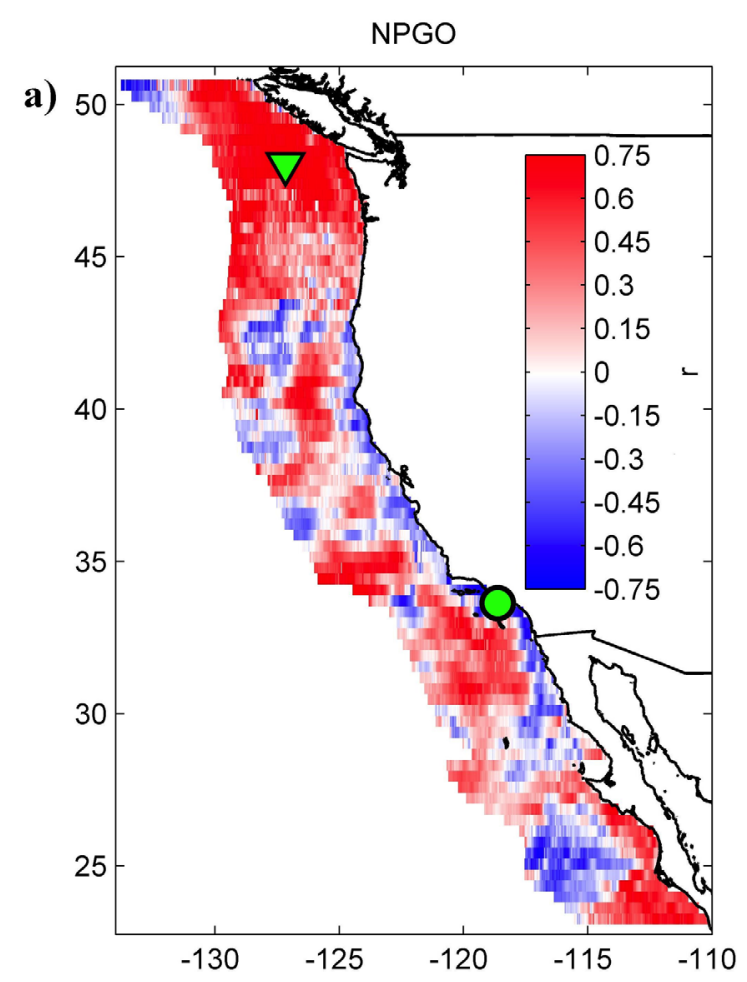

c)

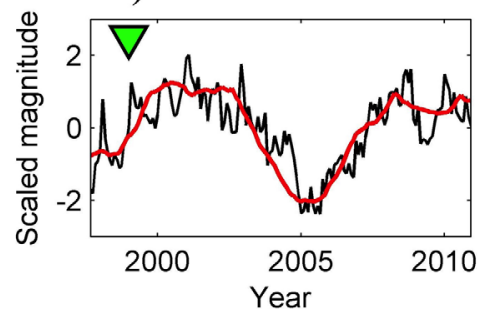

d)

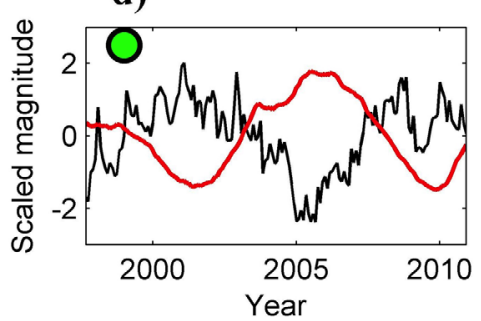

MEI

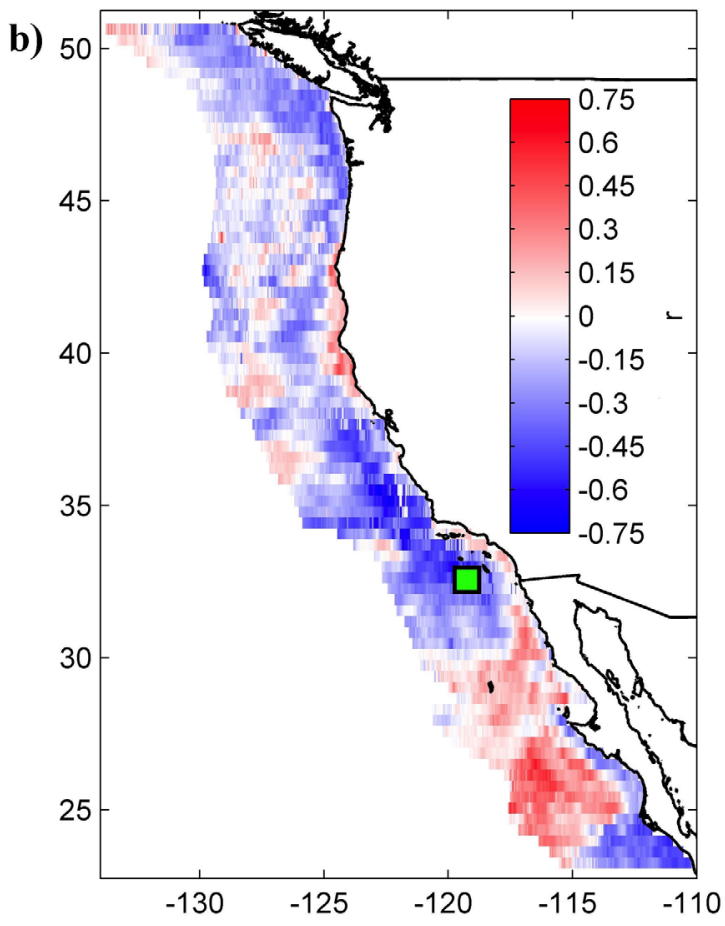

e)

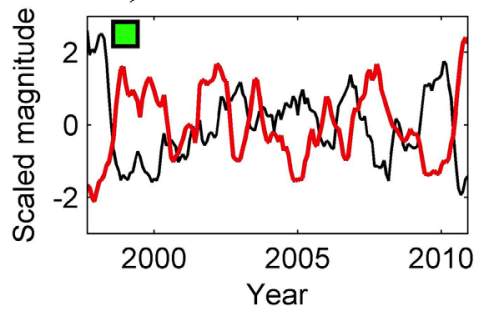

Figure 10. Location-specific relationships, as correlation coefficients, between the state-space chlorophyll trends over the study period and two Pacific climate indices: (a) the North Pacific Gyre Oscillation and (b) the Multivariate ENSO Index. Both series were detrended with a least-squares fit straight-line linear model prior to correlation calculations. Examples of their relationship in highly correlated regions (green symbols) as (c and d) individual chlorophyll trend time series (red) and the NPGO and (e) the MEI (black) are shown, scaled by their respective standard deviations.

the second mode of North Pacific basin-scale SST and sea level height anomaly variability, captures variability in the gyre circulation and has positive relationships to upwelling timing [Chenillat et al., 2012] and in situ measured chlorophyll concentrations off Southern California [Di Lorenzo et al., 2008]. The spatial pattern of the NPGO on chlorophyll background trends (Figure 10a) shows strongest positive correlations along the southern Baja California coastal upwelling region south of Punta Eugenia and in the northern portion of the study area off British Columbia and northern Washington (example, Figure 10c). This pattern is consistent with previous work [Thomas et al., 2009] based on correlations of simple zonally averaged chlorophyll anomalies. Weaker positive correlations are also evident in a broad region offshore of Southern California, consistent with the relationship shown by Di Lorenzo et al. [2008] that is a spatial mean of chlorophyll over the whole California Cooperative Oceanic Fisheries Investigations (CalCOFI) region. The satellite data analyzed here are able to reveal location-specific details. The NPGO is associated with strong cross-shelf differences in chlorophyll response throughout the main upwelling regions between southern Oregon and Punta Eugenia. Negative correlations are present all along the upwelling zone within $\sim 100 \mathrm{~km}$ of the coast (example, Figure 10d), separated from weaker or positive correlations offshore. Correlations of chlorophyll trends with the MEI are negative over most of the study area and lack such cross-shelf structure in most regions. Correlations are strongest off northern Washington and off central and southern California $\sim 37^{\circ} \mathrm{N}-30^{\circ} \mathrm{N}$ (example, Figure 10e) where they extend to the western extent of the study region. The positive correlations are evident offshore of southern Baja California, in regions associated with the offshore 1997-1998 El Niño chlorophyll increase [Kahru and Mitchell, 2000]. Over the time period studied here, the Pacific Decadal Oscillation (PDO) is strongly correlated with the MEI, and its linkage to background chlorophyll trends (not shown) looks similar to that of the MEI in both 
spatial pattern and magnitude. Correlations between the dominant modes of study area trends isolated by the EOF time series in Figure 6 and the NPGO and MEI support these views. The (detrended) dominant EOF mode of trends (Mode 1, Figure 6a) tracks both the NPGO $(\mathrm{r}=0.63)$ and the MEI $(\mathrm{r}=-0.60)$ over the study period. Not surprisingly, the patterns of chlorophyll relationship to these climate signals revealed by the state-space model trends are substantially similar to those relating the same climate indices to simple nonseasonal chlorophyll [Thomas et al., 2012]. Although the time scales of these relationships are short by climate standards, they do point to differing roles in California Current ecosystem control for these two modes of North Pacific variability, widespread and synchronous for the MEI (and PDO), but with stronger latitudinal differences and enhancing cross-shelf gradients for the NPGO. This latter pattern is consistent with an association of the NPGO to the ecosystem through upwelling dynamics [Di Lorenzo et al., 2008; Chenillat et al., 2012].

\section{Summary}

[34] Previous work suggests that chlorophyll concentrations in parts of the California Current are increasing. This is evident in multidecadal field data for a specific region, the Southern California region sampled by the CalCOFI program, and over a more extensive region over the past decade viewed by satellite ocean color data. Previous satellite-based analyses of trends in the California Current used monthly anomalies, where potentially nonstationary seasonal cycles and episodic events might bias or obscure long-term trends. Although we recognize that both seasonal and episodic signals are potential components of long-term change, here we isolate the slowly varying background trend underlying these signals. The state-space model results are consistent with these previous studies, but by isolating background trends from higher-frequency variability, they expand the spatial extent of these positive trending regions, showing that most of the California Current region experienced increasing chlorophyll concentrations over the SeaWiFS mission period. These trends have distinct spatial patterns reflecting different characteristics of decadal-scale ecosystem change, strongest off the Pacific Northwest and off central California, weakest in offshore areas in the west of the study area. Off Baja California, trends are either very weak or decreasing. These signals were still present, and significant, but of weaker magnitude when the El Niño period at the beginning of the time series is removed.

[35] Direct local environmental linkages to this increasing chlorophyll trend are not obvious in comparisons made here, a conclusion also presented by Kahru et al. [2009]. Increasing upwelling favorable winds are evident at most latitudes, but the trends at all locations except those of northern California are weak. Decreasing coastal SST through most of the latitudinal range also suggests increased upwelling, but again, at latitudes south of $44^{\circ} \mathrm{N}$, these SST trends are weak. Not quantified here are other possible trends that would impact chlorophyll, among them changes in grazing pressure, circulation changes that would change advection into the region and changes in nutrient concentrations in upwelled water. Exploration of such interactions is the territory of ongoing efforts in coupled physical biogeochemical modeling. The regionally specific results presented here provide both a time and space validation for such models at one trophic level of the ecosystem.

[36] Acknowledgments. We thank M. Di Lorenzo and other co-PIs on the U.S. GLOBEC project POBEX (http://pobex.org) for continuing interaction and many helpful discussions and the NASA Ocean Color group for access to the SeaWiFS data. Martyna Marczak and Victor Gomez provided assistance on the MATLAB implementation of statespace models. Three reviewers provided valuable comments and questions resulting in a clearer presentation. Funding for this work was provided by NSF as part of the U.S. GLOBEC Project with grants to ACT (OCE0815051 and OCE-0814413). US GLOBEC contribution number 733.

\section{References}

Aksnes, D. L., and M. D. Ohman (2009), Multi-decadal shoaling of the euphotic zone in the southern sector of the California Current System, Limnol. Oceanogr., 54(4), 1272-1281.

Antoine, D., A. Morel, H. R. Gordon, V. F. Banzon, and E. H. Evans (2005), Bridging ocean color observations of the 1980s and 2000s in search of long-term trends, J. Geophys. Res., 110, C06009, doi:10.1029/ 2004JC002620

Bakun, A. (1990), Global climate change and intensification of coastal ocean upwelling, Science, 247(4939), 198-201.

Bakun, A., and C. S. Nelson (1991), The seasonal cycle of wind-stress curl in subtropical eastern boundary current regions, J. Phys. Oceanogr., 2l(12), 1815-1834.

Barth, J. A., B. A. Menge, J. Lubchenco, F. Chan, J. A. Bane, A. R. Kirincich, M. A. McManus, K. J. Nielsen, S. D. Pierce, and L. Washburn (2007), Delayed upwelling alters nearshore coastal ocean ecosystems in the northern California current, Proc. Natl. Acad. Sci. U. S. A., 104(10), 3719-3724

Belkin, I. M. (2009), Rapid warming of large marine ecosystems, Prog. Oceanogr., 81(1-4), 207-213.

Bograd, S. J., and R. J. Lynn (2003), Anomalous subarctic influence in the southern California Current during 2002, Geophys. Res. Lett., 30(15), 8020, doi:10.1029/2003GL017446.

Bograd, S. J., I. Schroeder, N. Sarkar, X. M. Qiu, W. J. Sydeman, and F. B. Schwing (2009), Phenology of coastal upwelling in the California Current, Geophys. Res. Lett., 36, L01602, doi:10.1029/2008GL035933.

Boyce, D. G., M. R. Lewis, and B. Worm (2010), Global phytoplankton decline over the past century, Nature, 466, 591-596, doi:10.1038/ nature09268.

Burrows, M. T., et al. (2011), The pace of shifting climate in marine and terrestrial ecosystems, Science, 334(652), 652-655, 10.1126/science.1210288.

Campbell, J. W. (1995), The lognormal distribution as a model for biooptical variability in the sea., J. Geophys. Res., 100, 13,237-13,254.

Chavez, F. P., J. T. Pennington, C. G. Castro, J. P. Ryan, R. P. Michisaki, B. Schlining, P. Walz, K. R. Buck, A. McFadyen, and C.A. Collins (2002), Biological and chemical consequences of the 1997-1998 El Niño in central California waters, Prog. Oceanogr., 54(1-4), 205-232.

Chenillat, F., P. Riviere, X. Capet, E. Di Lorenzo, and B. Blanke (2012), North Pacific Gyre Oscillation modulates seasonal timing and ecosystem functioning in the California Current upwelling system, Geophys. Res. Lett., 39, L01606, doi:10.1029/2011GL049966.

Cloern, J. E., et al. (2010), Biological communities in San Francisco Bay track large-scale climate forcing over the North Pacific, Geophys. Res. Lett. 37, L21602, doi:10.1029/2010GL044774.

Commandeur, J. J. F., and S. J. Koopman (2007), An Introduction to State Space Time Series Analysis, Oxford Univ. Press, Oxford, U. K.

Commandeur, J. J. F., S. J. Koopman, and M. Ooms (2011), Statistical software for state space methods, J. Stat. Software, 41, 1-18. [Available at http://www.jstatsoft.org/v41/i01/.]

de Valpine, P., and J. A. Rosenheim (2008), Field-scale roles of density, temperature, nitrogen, and predation on aphid population dynamics, Ecology, 89(2), 532-541.

Denman, K. L., and H. J. Freeland (1985), Correlation scales, objective mapping and a statistical test of geostrophy over the continental shelf, J. Mar. Res., 43(3), 517-539.

Di Lorenzo, E., A. J. Miller, N. Schneider, and J. C. McWilliams (2005), The warming of the California Current system: Dynamics and ecosystem implications, J. Phys. Oceanogr., 35, 336-362. 
Di Lorenzo, E., et al. (2008), North Pacific Gyre Oscillation links ocean climate and ecosystem change, Geophys. Res. Lett., 35, L08607, doi: 10.1029/2007GL032838.

D’Ortenzio, F., D. Antoine, E. Martinez, and M. R. d'Alcala (2012), Phenological changes of oceanic phytoplankton in the 1980s and 2000s as revealed by remotely sensed ocean-color observations, Global Biochem. Cycles, 26, GB4003, doi:10.1029/2011GB004269.

Durbin, J., and S. J. Koopman (2001), Time Series Analysis by State Space Methods, Oxford Univ. Press, Oxford, U. K.

Espinosa-Carreon, T. L., P. T. Strub, E. Beier, F. Ocampo-Torres, and G. Gaxiola-Castro (2004), Seasonal and interannual variability of satellite-derived chlorophyll pigment, surface height, and temperature off Baja California, J. Geophys. Res., 109, C03039, doi:10.1029/ 2003JC002105.

Fiedler, P. C., R. Mendelssohn, D. M. Palacios, and S. J. Bograd (2012), Pycnocline variations in the eastern tropical and North Pacific, 19582008, J. Clim., 583-599, doi:10.1175/JCLI-D-11-00728.1.

Foreman, M. G. G., B. Pal, and W. J. Merryfield (2011), Trends in upwelling and downwelling winds along the British Columbia shelf, J. Geophys. Res., 116, C10023, doi:10.1029/2011JC006995.

Garcia-Reyes, M., and J. L. Largier (2010), Observations of increased wind-driven coastal upwelling off central California, J. Geophys. Res., 115, C04011, doi:10.1029/2009JC005576.

Hazen, E. L., S. Jorgensen, R. R. Rykaszewski, S. J. Bograd, D. G. Foley, I. D. Jonsen, S. A. Shaffer, J. Dunne, D. P. Costa, L. B. Crowder, and B. A. Block (2012), Predicting habitat shifts of Pacific top predators in a changing climate, Nat. Clim. Change, 1-5, doi:10.1038/NCLIMATE1686.

Harvey, A. C., and J. Durbin (1986), The effects of seat belt legislation on British road casualties: A case study in structural time series modeling, J. R. Stat. Soc., Ser. A, 149(3), 187-227.

Hickey, B. M. (1998), Coastal oceanography of western North America from the tip of Baja California to Vancouver Island, in The Sea: The Global Coastal Ocean, edited by A. R. Robinson and K. H. Brink, pp. 345-393, Harvard Univ. Press, Cambridge, Mass.

Irwin, A. J., and M. J. Oliver (2009), Are ocean deserts getting larger?, Geophys. Res. Lett., 36, L18609, doi:10.1029/2009GL039883.

Ji, R. B., M. Edwards, D. L. Mackas, J. A. Runge, and A. C. Thomas (2010), Marine plankton phenology and life history in a changing climate: Current research and future directions, J. Plankton Res., 32(10), 1355-1368

Jonsen, I. D., R. A. Myers, and J. M. Flemming (2003), Meta-analysis of animal movement using state-space models, Ecology, 84(11), 30553063.

Jonsen, I. D., J. M. Flemming, and R. A. Myers (2005), Robust state-space modeling of animal movement data, Ecology, 86(11), 2874-2880.

Kahru, M., and B. G. Mitchell (1999), Empirical chlorophyll algorithm and preliminary SeaWiFS validation for the California Current, Int. J. Remote Sens., 20, 3423-3429.

Kahru, M., and B. G. Mitchell (2000), Influence of the 1997-98 E1 Niño on the surface chlorophyll in the California Current, Geophys. Res. Lett., 27(18), 2937-2940

Kahru, M., and B. G. Mitchell (2001), Seasonal and nonseasonal variability of satellite-derived chlorophyll and colored dissolved organic matter concentration in the California Current, J. Geophys. Res., 106(C2), 2517-2529.

Kahru, M., R. Kudela, M. Manzano-Sarabia, and B. G. Mitchell (2009), Trends in primary production in the California Current detected with satellite data, J. Geophys. Res., 114, C020074, doi:10.1029/2008JC004979.

Kahru, M., R. M. Kudela, M. Manzano-Sarabia, and B. G. Mitchell (2012), Trends in the surface chlorophyll of the California Current: Merging data from multiple ocean color satellites, Deep Sea Res. Part II, 77-80, 89-98.

Kim, H. J., A. J. Miller, J. McGowan, and M. L. Carter (2009), Coastal phytoplankton blooms in the Southern California Bight, Prog. Oceanogr., 82(2), 137-147.
Legaard, K., and A. C. Thomas (2006), Spatial patterns in seasonal and interannual variability of chlorophyll and surface temperature in the California Current, J. Geophys. Res., 111, C06032, doi:10.1029/ 2005JC003282.

Mackas, D., T. Strub, A. C. Thomas, and V. Montecino (2006), Eastern boundary currents, in The Sea: The Global Coastal Ocean, edited by A. R. Robinson and K. H. Brink, pp. 21-60, Harvard Univ. Press, Cambridge, Mass.

Mackas, D. L. (2006), Interdisciplinary oceanography of the western North American continental margin, in The Sea: The Global Coastal Ocean, edited by A. R. Robinson and K. H. Brink, pp. 441-501, Harvard Univ. Press, Cambridge, Mass.

Martinez, E., D. Antoine, F. D’Ortenzio, and B. Gentili (2009), Climatedriven basin-scale decadal oscillations of oceanic phytoplankton, Science, 326(5957), 1253-1256.

McQuatters-Gollop, A., et al. (2011), Is there a decline in marine phytoplankton?, Nature, 472, E6-E7, doi:10.1038/nature09950.

Mendelssohn, R., and F. B. Schwing (2002), Common and uncommon trends in SST and wind stress in the California and Peru-Chile current systems, Prog. Oceanogr., 53, 141-162.

Mendelssohn, R., F. B. Schwing, and S. J. Bograd (2003), Spatial structure of subsurface temperature variability in the California Current, 19501993, J. Geophys. Res., 108, 3093, doi:10.1029/2002JC001568.

Mendelssohn, R., S. J. Bograd, F. B. Schwing, and D. M. Palacios (2005), Teaching old indices new tricks: A state-space analysis of El Niño related climate indices, Geophys. Res. Lett., 32, L07709, doi:10.1029/ 2005GL022350.

O'Reilly, J. E., S. Maritorena, B. G. Mitchell, D. A. Siegel, K. L. Carder, S. A. Garver, M. Kahru, and C. McClain (1998), Ocean color chlorophyll algorithms for SeaWiFS, J. Geophys. Res., 103(C11), 24,937-24,953.

Palacios, D. M., S. J. Bograd, R. Mendelssohn, and F. B. Schwing (2004), Long-term and seasonal trends in stratification in the California Current, 1950-1993, J. Geophys. Res., 109, C10016, doi:10.1029/2004JC 002380 .

Rousseeuw, P. (1987), Silhouettes: A graphical aid to the interpretation and validation of cluster analysis, J. Comput., Appl. Math., 20, 53-65.

Schwing, F. B., and R. Mendelssohn (1997), Increased coastal upwelling in the California Current system, J. Geophys. Res., 102(C6), 12,78512,786

Thomas, A. C., P. T. Strub, and P. Brickley (2003), Anomalous satellitemeasured chlorophyll concentrations in the northern California Current in 2001-2002, Geophys. Res. Lett., 30(15), 8022, doi:10.1029/2003GL 017409 .

Thomas, A. C., P. Brickley, and R. Weatherbee (2009), Interannual variability in chlorophyll concentrations in the Humboldt and California current systems, Prog. Oceanogr., 83(1-4), 386-392.

Thomas, A. C., P. T. Strub, R. A. Weatherbee, and C. James (2012), Satellite views of Pacific chlorophyll variability: Comparisons to physical variability, local versus nonlocal influences and links to climate indices, Deep Sea Res. Part II, 77-80, 99-116.

Vantrepotte, V., and F. Melin (2009), Temporal variability of 10-year global SeaWiFS time-series of phytoplankton chlorophyll a concentration, ICES J. Mar. Sci., 66, 1547-1556.

Vantrepotte, V., and F. Melin (2011), Inter-annual variations in the SeaWiFS global chlorophyll a concentration (1997-2007), Deep Sea Res. Part I, 58(4), 429-441.

Wang, G., and L. L. Getz (2007), State-space models for stochastic and seasonal fluctuations of vole and shrew populations in east-central Illinois, Ecol. Modell., 207(2-4), 189-196.

Wang, J., H. Liang, and R. Chen (2012), A state space model approach for HIV infection dynamics, J. Time Ser. Anal., 33, 841-849.

Ware, D. M., and R. E. Thomson (2005), Bottom-up ecosystem trophic dynamics determine fish production in the northeast Pacific, Science, 308(5726), 1280-1284. 